Towards A Planning Model For Rural Women Leaders' Dealing With Social Services For Older Women . A study Applied To rural pioneers in Qena Governorate

\author{
نحو نموذج تخطيطي لتعامل الرائدات الريفيات مع الخدمات الاجتماعية المقدمة

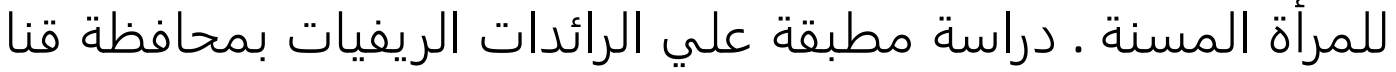 \\ Prof Ahmed Hamdy Shora Tawfik
}

Planning Professor, Undersecretary of the Higher Institute of Social Work in Qena - 2017 -

Introduction and the study problem :

The planning of social services is one of the most important pillars of Egyptian society, and it is also one of the real concerns of the Egyptian state in the current and future phase ,This is because this portal plays a prominent role in the reform and development of the service system in Egyptian society, and the statistics tell us what is expected in the future of the need to take care of the elderly and to take care of the issue of integrated care for them and develop policies and plans to provide care for them . From a planning point of view, there are those who believe that the social worker should develop a plan and work to achieve it to improve the standard of living of the elderly with whom he works, and in many estimation, the plans of the elderly have not yet received the attention they deserve . So the issue of planning social services is one of the most important issues for the systematic development of social planning of social service institutions, and since rural women are the link between the villagers, including the elderly and the executive bodies at the level of the countryside and the Egyptian village.

Therefore, the current study seeks to try to develop a planning model for the treatment of rural women with social services provided to older women, and to identify the most important obstacles to the services of the services of the care of older women, the most important forms of activating programs of services for the care of older women, and the most important proposals to develop action plans Rural women in the field of caring for older women.

\section{The Aims Of Study:}

1- The government's work on the women's rights programme is based on the government's approach to the development of a gender equality system .

2- Learn about the most important social services provided to older women by rural women .

3- Learn about the most important images of activating the programs of services for the care of the elderly.

4- Identify the most important obstacles to the services of the services of the care of older women.

5- Learn about the most important proposals for developing the action plans of rural women leaders in the field of caring for older women .

\section{.The Study Questions :}

1- What are the most important steps in the planning model for rural women to deal with social services for older women?

2- What are the most important social services provided to older women by rural women?

3- What are the most important forms of activating the programs of services 
for the care of older women?

4- What are the most important obstacles to the services of the services of the care programs for the elderly?

5- What are the most important proposals for developing the action plans of rural women leaders in the field of caring for older women?

The Study Conceptions : Model - A Planning Model - Social Services.

\section{.Methodology Procedures :}

$\checkmark$ Type of the study : A descriptive and analytical study .

$\checkmark$ The used method: The study used a comprehensive social survey method

$\checkmark$ The Study Tools : Questionnaire applied to rural women in Qena governorate

\section{The Study Fields :}

The Local Field : Applied study on rural pioneers in Qena governorate
The Human Field : The questionnaire was applied to a number of (63) individuals out of the total number of (71) rural leaders in Qena governorate .

The timing Field : The field study was performed from 2/4/2017 until 12/4/2017.

\section{The Study Results :}

- The results showed the most important steps of the planning model for the treatment of rural women with social services provided to older women, the most important social services provided to older women by rural pioneers, and the most important needs of the programs of older women, The most important forms of activation of the programs of services for the care of older women, the most important obstacles to the services of the services of the care of older women, and the most important proposals to develop the action plans of rural women leaders in the field of care of older women. 
نحو نموذج تخطيطي لتعامل الرائدات الريفيات مع الخدمات الاجتماعية

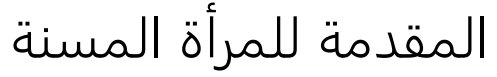
دراسة مطبقة علي الرائدات الريفيات بمحافظة قنا

\author{
إعداد

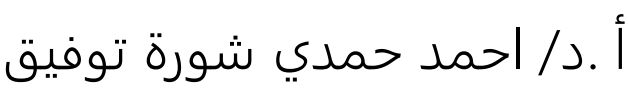

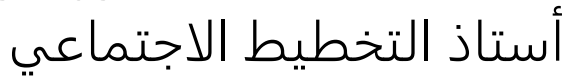 \\ وكيل المعهد العالي للخدمة الاجتماعية بقنا للتدريب والشباب الشباب
}

أولا: مقدمة ومشكلة الدراسة :

يعد التخطيط للخدمات الاجتماعية أحد الركائز الهامة للمجتمع المصري , كما يعد من الاهتمامات الحقيقية

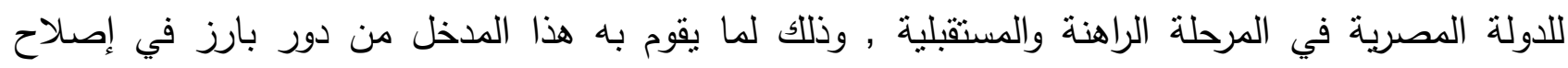

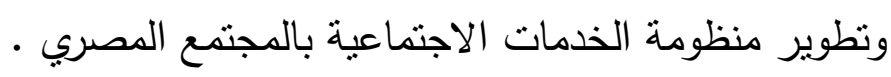

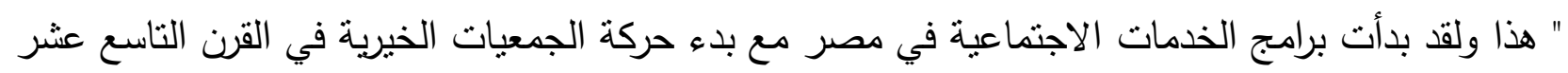

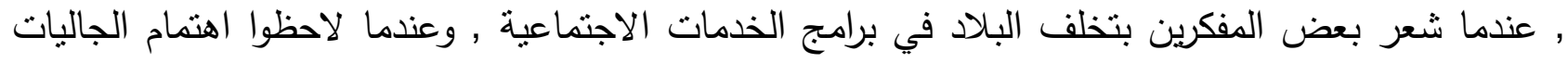

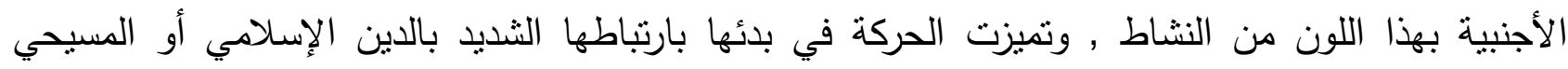

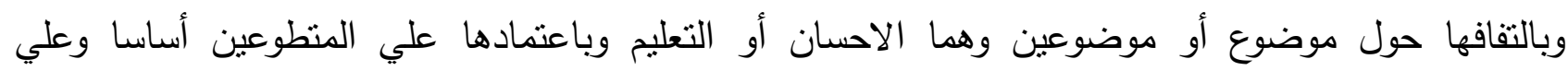

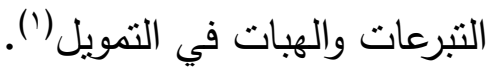

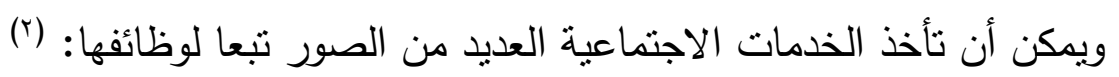

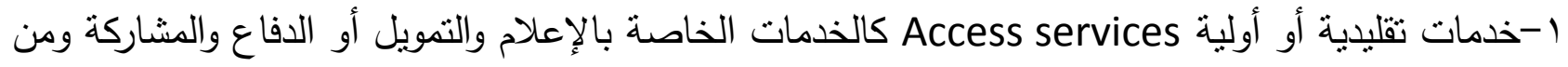

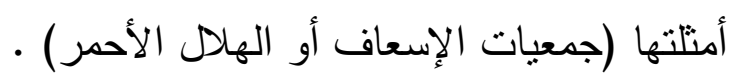

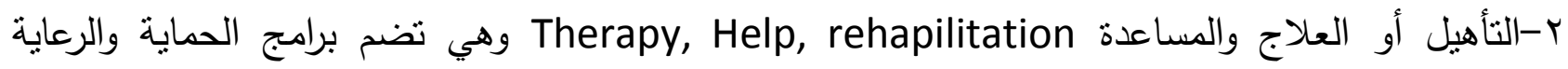
الاجتماعية ومن أمتلنها (المجالس والاتحادات , رعاية الطفولة ، الخدمة الاجتماعية في المجال المدرسي والطبي - البرامج الخاصة بتعديل السلوك ، وبرامج الحماية للمسنين) •

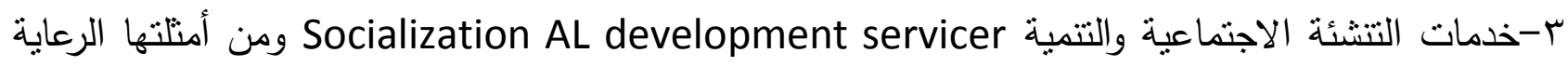
اليومية للأطفال ، والتخطيط للأسرة , ومراكز الاحياء ، وبرامج التعليم للأسرة.

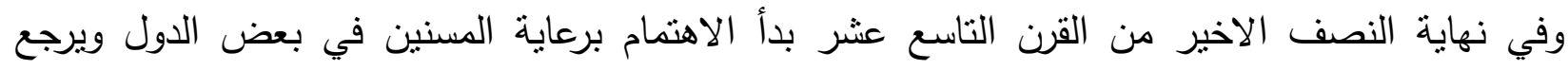

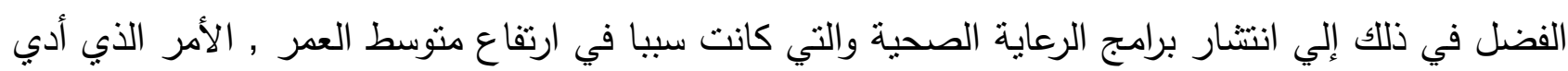


إلي الاهتمام بهذه الفئة الجديدة (؟)، ثم بدأت الأجهزة التتفيذية ممنلة في وزارة التضامن الاجتماعي , والأجزة

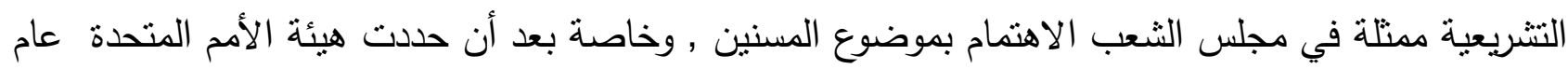

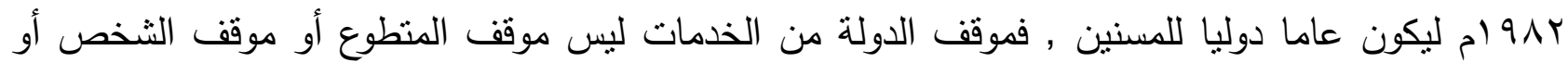
الهيئة المتطوعة لعمل الخير , بل هي الثخصية المعنوية التي يلزم أجهزتها بتلاك الرعاية , والتي نلزم المسنين

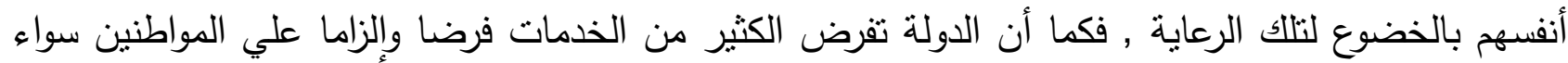

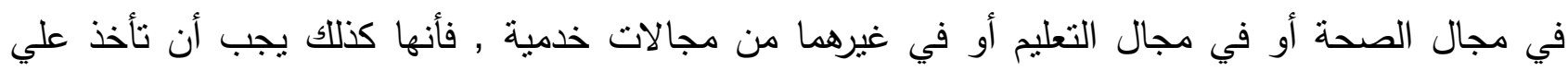

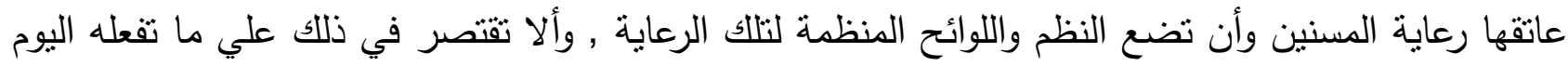

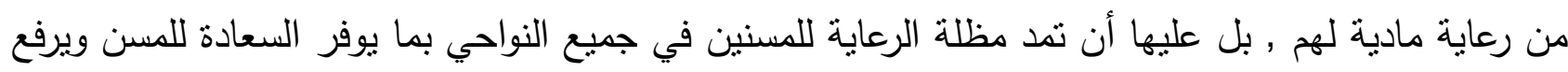
من روحه المعنوية (ई). وتخبرنا الإحصاءات بما هو منوقع مستقبلا , فليست هناك حروبا عالمية أخري ولكن مخاطر الزيادة المتوقعة للمسنين هو ما يخشاه الجميع , بما تمثلك تلك الزيادة من انعكاسات علي التتمية الاجتماعية

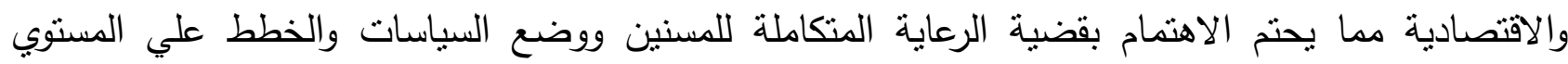
المحلي والقومي لنوفير الرعاية الصحية والاجتماعية والاقتصادية لهم (0).

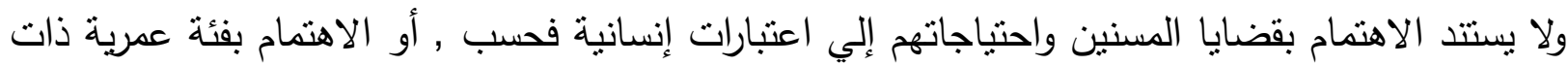

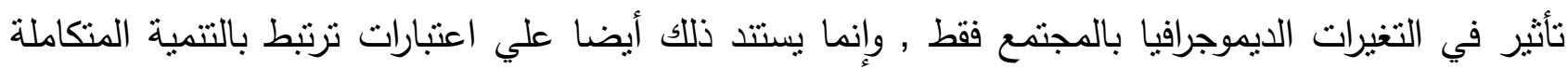

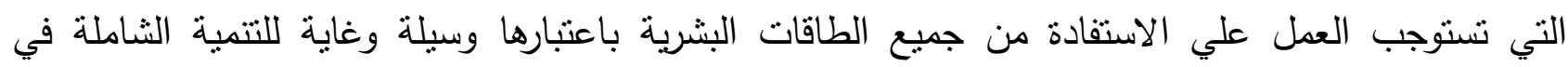

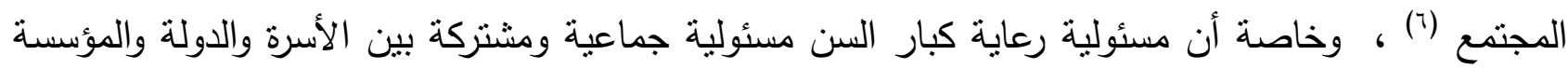

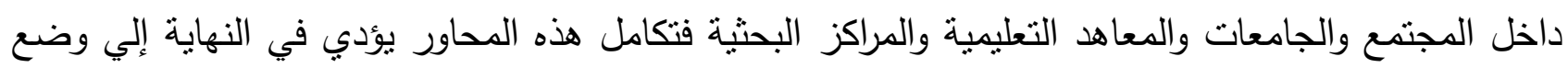
البرامج العلمية المدروسة ويضمن لها النجاح في التتفيذ (v). هذا ولقد تعددت الدراسات التي اهتمت بالمسنين ومنها : دراسة قوت القلوب محمد فريد النجار , وفي عام الترات

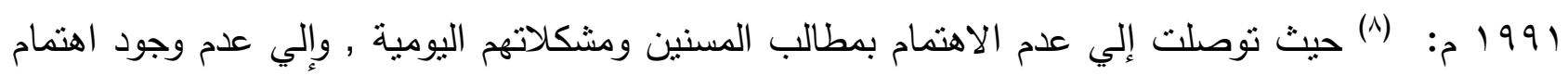

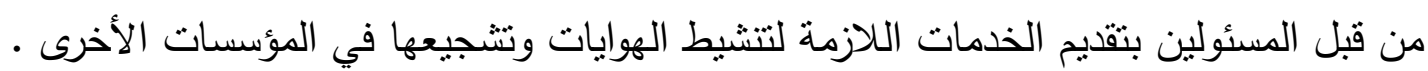

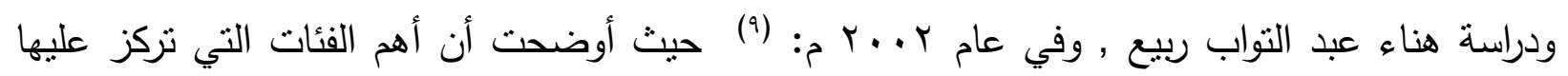

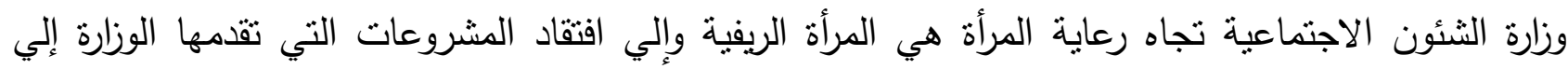

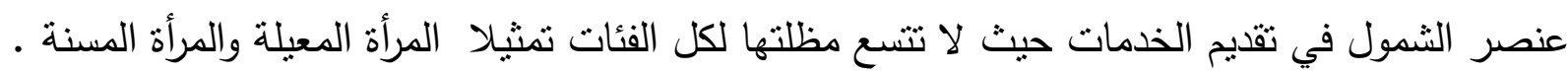

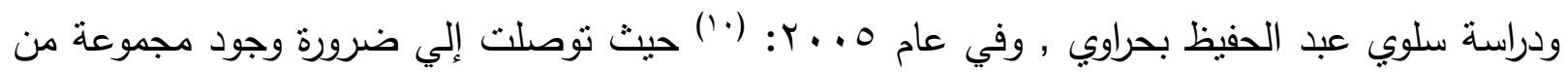
المتخصصين ( الاخصائيين الاجتماعيين ) الذين يقومون بتوعية أهالي القرية وتحديد حاجات ومشكلات 
المسنين في القرية , وإلي ضرورة توفير فرص عمل مناسبة داخل القرية لمحاولة استثار طاقات وخبرات المسنين , وإلي تذعيم الخدمات الصحية والنفسية والاقتصادية غير الرسمية للمسنين بالريف . ودراسة سمر صبحي عمر يوسف , وفي عام V. . . م : ('l') حيث توصلت إلي أنه توجد علاقة ايجابية ذات دلالة احصائية بين استخدام برنامج التخخل المهني من منظور الممارسة العامة للخدمة الاجتماعية والتخفيف من عزلة المسن وانسحابه من الحياة الاجتماعية لزيادة أداؤه الاجتماعي • ودراسة حسن عبد الوهاب محمود عبداله , وفي عام 9 . . r م : (rاحيث توصلت إلي عدم صحة الفرض الرئيسي للدراسة والقائل بأنه لا توجد علاقة بين كفاءة أندية المسنين في تقديم خدماتها وبين تحسين نوعية حياة أعضائها , حيث وجدت الدراسة أن هناك علاقة قوية جدا ايجابية ذات دلالة احصائية بين كفاءة أندية المسنين

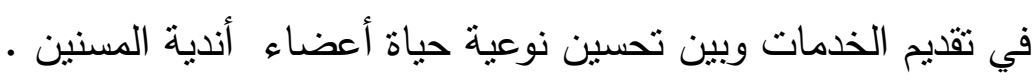

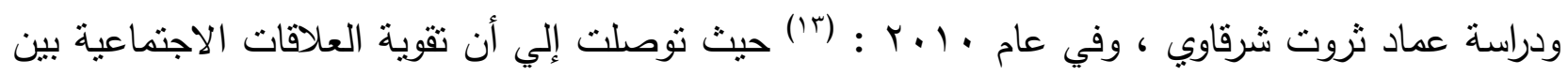
المسنين وبعضهم وأسرهم والمجتمع الذين يعيشون فيه من أهم القيم التي يجب أن يلتزم بها الأخصائي الاجتماعي الاعن

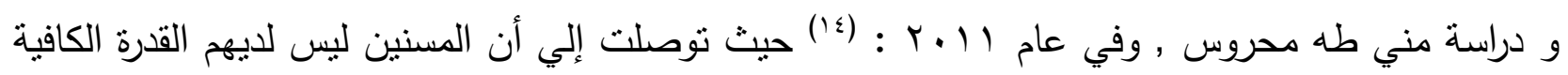
على التوصل والمشاركة مع الاخرين , وإلي أنه توجد علاقة إيجابية بين برنامج التذخل المهني للممارسة العامة في الخدمة الاجتماعية وتذعيم المشاركة والتواصل الاجتماعي للمسنين .

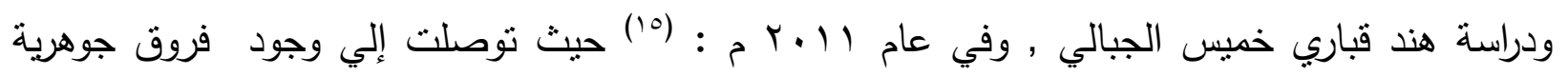
لاستخدام برنامج التذخل المهني مع جماعات المسنين فيما يتعلق باستثمار وقت الفراغ .

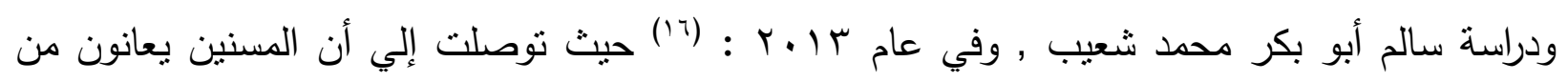
مشكلات اجتماعية خارج محيط الأسرة أكثز منه داخل محيط الاسرة , وإلي أن أكثز المتغيرات ارتباطا بالمشكلات الاجتماعية للمسنين هي : النوع - الحالة الاجتماعية - الدخل .

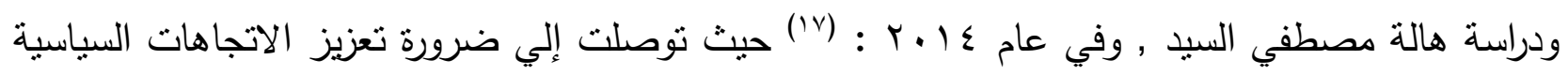
والثعبية والاجتماعية نحو المسنين كطاقة قادرة على العطاء وليست كطاقة معالجة أو مستهلكة , وإلي أنه يجب العمل من خلال أساليب البحث العلمي على تفهم الأسباب والعوامل التقافية التي تحد من استفادة المسنين من الخدمات المتاحة في المجتمع , والعمل علي إزالة هذه الاسباب والتخفيف من حدتها وصولا إلي أقصي كفاءة ممكنة في برامج رعاية المسنين. ودراسة فاطمة الزهراء عبد ربه أحمد , وفي عام 0 • ب : (^’) حيث توصلت إلي أهمية إثباع الاحتياجات التدريبية المرتبطة بمهارات التسويق الاجتماعي للأخصائي الاجتماعي لجذب المسنين للاستفادة من خدمات 
أندية الرعاية والتي تتمنل في الاحتياجات المعرفية ، والاحتياجات القيمية , والاحنياجات المهنية , والاحتياجات المهارية . وبصورة أكثر تطورا هناك من يري - أن دعمت الخدمة الاجتماعية نشاطها في مجال رعاية المسنين بالعمل عال على الحفاظ على كرامتهم وتحريرهم من العوائق الاجتماعية معتبرة الثيخوخة حالة من القدرة والامكانية لا الضمور والاستسلام ، فالخدمة الاجتماعية مهنة انسانية توافرت لها كافة المقومات المهنية والعلمية التي تتيح

لها التذخل والتصدي لمشكلات المسنين ومد العون لهم ومساعدتهم على تتشيط قدراتهم واستعادة امكاناتهم (19) ومن الناحية التخطبطية هنالك دن يري أن يقوم الاخصائي الاجتماعي بوضع خطة وبعمل على إنجازها , لتحسين مستوي معيشة المسنين الذين يعمل معهم , وهذه الخطة تقوم على تقدير حجم كل مشكلة ودراستها وتتخيصها واكتشاف الأهداف الممكن تحقيقها والاختبارات المتاحة , فبعد فهم الموقف فإن الاخصائي الاجتماعي يجب عليه العمل بأمانة ودقة مع المسنين , وذلك بأشراكهم في عملية حل المشكلة ، وتعزيز قدراتهم في التغلب عليها, وتتمية جوانب القوة فيهم (r.)

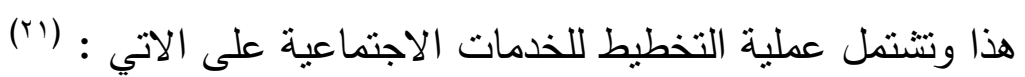
ا- التعرف على أماكن تواجد تجمعات الناس المعرضة للخطر ( أي الأكثر تعرضا للوقوع في مشاكل اجتماعية ) أو ترتيب التجمعات السكنية ( الثيخات / الأحياء ) طبقا لتعرضهم للخطر أو المشاكل الاجتماعية وهو

ما يعرف بالتحليل المكاني special analysis وتحديد الفئات المعرضة للخطر At Risk group ץ- التعرف على الحاجات الانسانية التي تحتاج لإشباع وهو ما يعرف بدراسات تقدير الاحتياجات وتحديد المشاكل طبقا لأولوبات مواجهتها . المبات r- التعرف على مؤسسات الخدمات القائمة حكومية أو أهلية والموارد المتاحة في كل منها وما يمكن توظيفه service inventories منها لمواجهة هذه الاحتياجات وحل هذه المشاكل وهو ما يعرف بتوصيف الموارد ع - البحث عن أنسب البرامج والتتظيمات أو المؤسسات التي يمكن بواسطتها أو من خلالها اشباع هذه الحاجات الانسانية بأفضل الطرق وبأقل التكاليف . ه- مشاركة المجتمع في ترتيب الاحتياجات وتخصيص الموارد واختيار أنسب البرامج عن طريق هيئاته • ومؤسساته " وعلي الرغم من ذلك فإن قضايا المسنين عديدة واحتياجاتهم ومشكلاتهم متعددة ، بل إن هناك قصور واضح في أوجه رعايتهم وقدرة المؤسسات الحكومية والاهلية التي تقوم على خدمته ورعايتهم , وعلى الرغم من ذلك وفي ظل التزايد الكبير في اعدادهم على المستوي العالمي والمحلي نأمل أن نولي الدولة والأجهزة المعنية برعايتهم مزيدا من الاهتمام لهذه الفئة الذين اعطوا حياتهم وجهدهم خدمة لمجتمعه (rr) ، وما زال المسنون لا 
يلقون في مجتمعنا العناية الكافية التي تتناسب مع وضعهم فيه أو مع دورهم الذي قاموا به في مراحل حياتهم

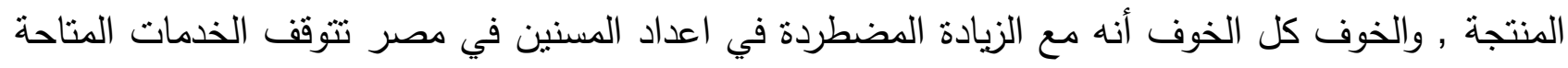
لهم أو تكاد تتجمد مما يؤدي إلي تفاقم المشكلة ويصبح من العسير مستقبلا مواجهتها أو نوفير الاحتياجات

اللازمة لها

وفي تقدير كثيرين أن خطط المسنين - سواء في مصر والخارج - لم تلق حتي الان ما تستحق من اهتمام

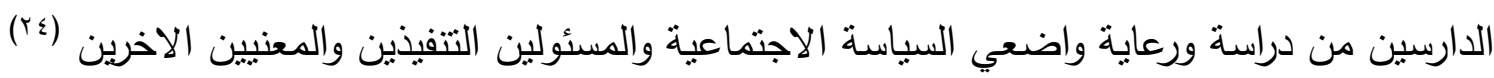

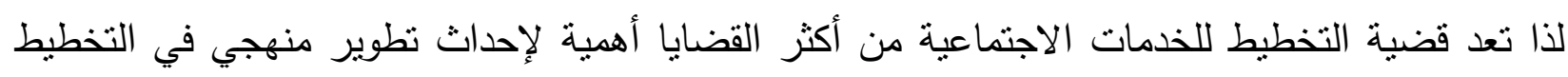
الاجتماعي لمؤسسات الخدمة الاجتماعية ، وهو يعد مدخل هام لتقدم وتطور الخدمات المقدمة للأفراد

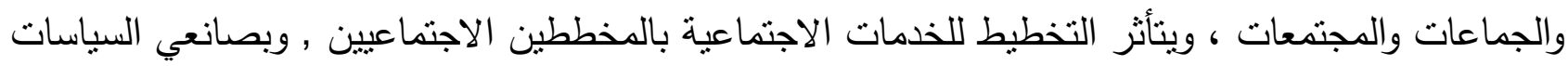

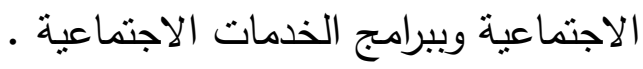
وهي - أي التخطيط للخدمات الاجتماعية - تعاني من بعض نقاط الضعف من أهمها : - - غياب التكامل بين جهود خطط التتمية المتكاملة .

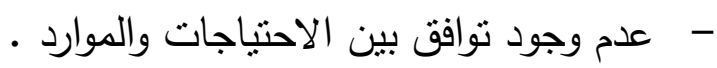

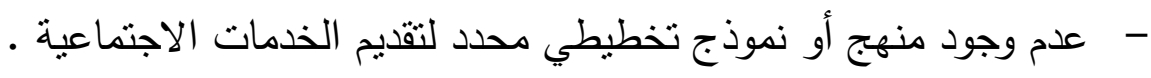

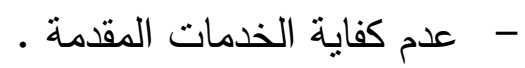
- - عدم التوظيف الجيد لعناصر العملية التخطيطية .

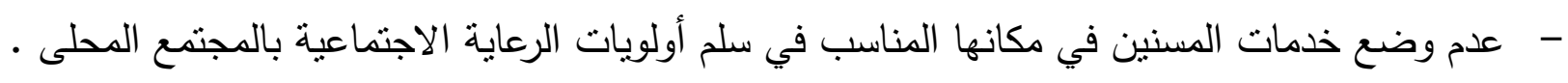
- عدم وجود تخطيط جيد لتوظيف إمكانات المسنين باعتبارهم موارد هامة بالمجتمع المحلي ل

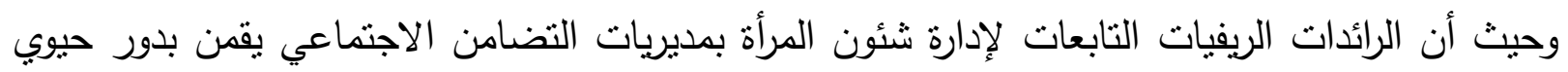

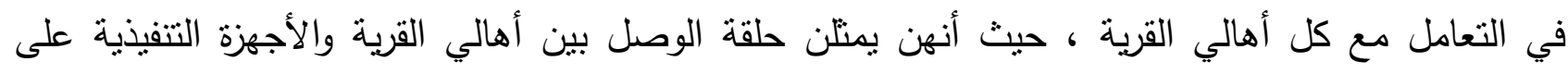

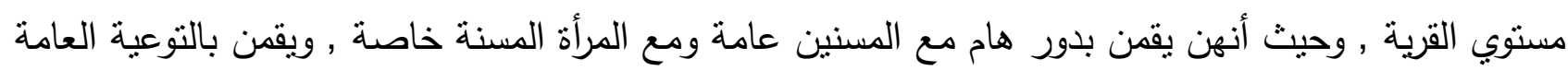

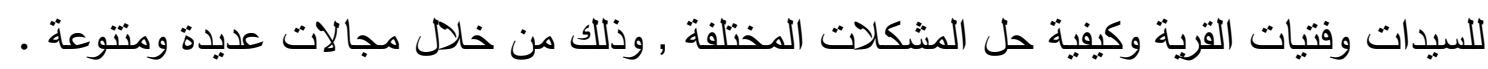

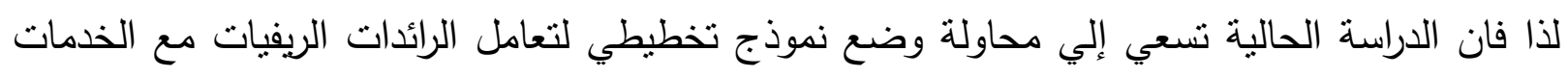

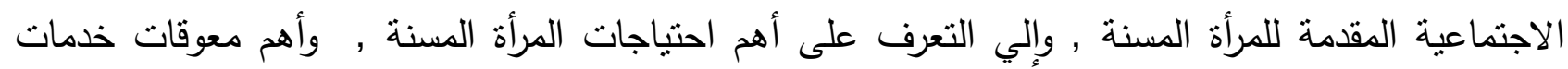

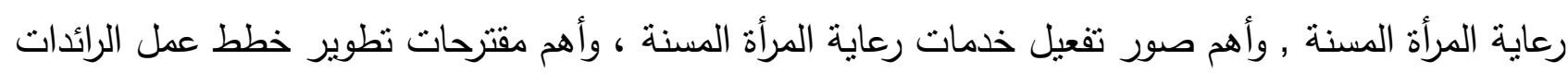

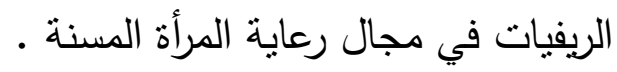




$$
\text { ثانيا : أهمية الدراسة : أهمية }
$$

1- أهمية التخطيط للخدمات الاجتماعية المقدمة للمسنين عامة وللمرأة المسنة خاصة . أهنة ץ- أهمية التخطيط والتوظيف الجيد لاستثمار المسنين كطاقة بشرية وقوة منتجة وليست قوة معولة بالمجتمع • المحلي r- اهتمام التخطيط الاجتماعي بدراسة الوضع الحالي للمسنين وأهم الخطط المستقبلية لتطوير الخدمات الاجتماعية المقدمة لهم . ع- أهمية رسم السياسات الاجتماعية وسن التشريعات المحفزة لرعاية المسنين وتقديم الخدمات الاجتماعية - اللائقة لهم

$$
\text { ثالثا : أهداف الدراسة : مداس }
$$

ا- محاولة وضع نموذج تخطيطي لتعامل الرائدات الريفيات مع الخدمات الاجتماعية المقدمة للمرأة المسنة. ץ- التعرف على أهم الخدمات الاجتماعية المقدمة للمرأة المسنة من خلال الرائدات الريفيات.

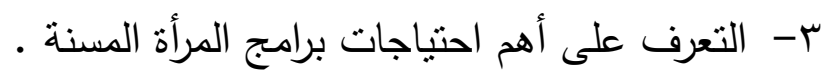
ع- التعرف على أهم البرامج التي يمكن للرائدة الريفية أن تقدها للمرأة المسنة . ه- التعرف على أهم صور تفعيل برامج خدمات رعاية المرأة المسنة . 7- تحديد أهم معوقات خدمات برامج رعاية المرأة المسنة . - Vحديد أهم مفترحات تطوير خطط عمل الرائدات الريفيات في مجال رعاية المرأة المسنة.

$$
\text { رابعا : تساؤلات الدراسة : }
$$

- ما أهم خطوات النموذج التخطيطي لتعامل الرائدات الريفيات مع الخدمات الاجتماعية المقدمة للمرأة المسنة؟ - ما مأهم الخدمات الاجتماعية المقدمة للمرأة المسنة من خله الرائدات الريفيات ؟

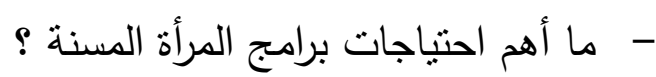
- - ما أهم البرامج التي يمكن للرائدة الريفية أن تقدمها للمرأة المسنة ؟ باهُه

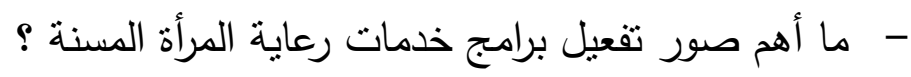

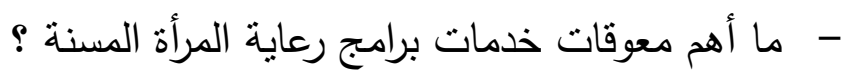
- ما أهم مقترحات تطوير خطط عمل الرائدات الريفيات في مجال رعاية المرأة المسنة ؟ 
خامسا : مفاهيم الدراسة : مفهوم النموذج : هو نمط علاقي يوضح العوامل والمتغيرات التي تئثر في حدوث موقف معين ودرجة

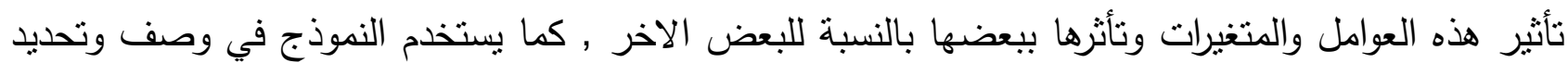

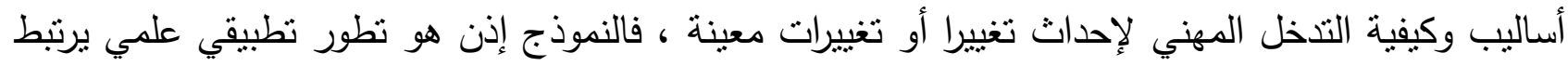

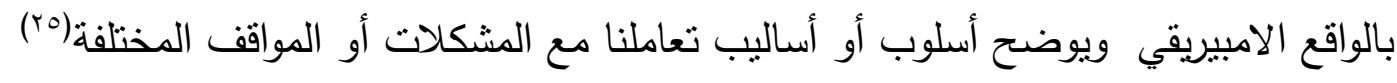

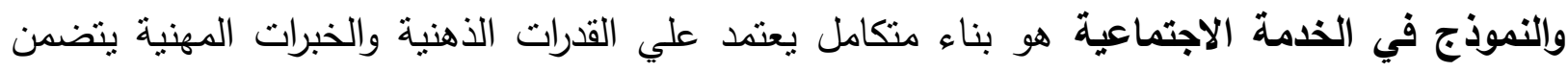
الأهداف والإجراءات والممارسات التي يقوم بها الاخصائي والمستهدفين من الممارسة ( العميل - الجماعة -

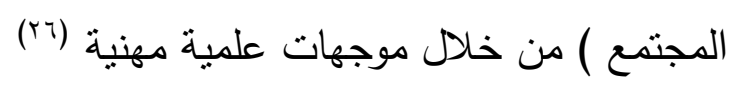

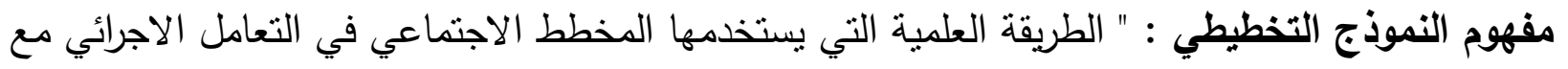
كافة عناصر الخطة لتحقيق الاختيار الأنسب للخدمات والبرامج والمشروعات الششبعة للاحتياجات والمعالجة

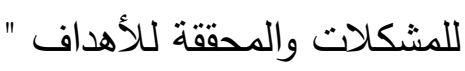

\section{مفهوم النموذج التخطيطي (اجرائيا) :}

- هو بناء علمي يعتمد علي مراحل وخطوات تتفيذية تحقق أهداف الخطة المطلوبة .

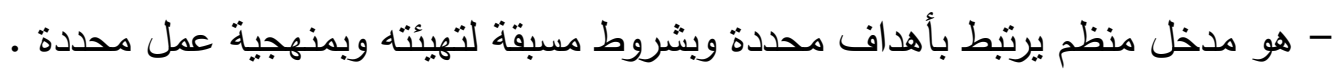

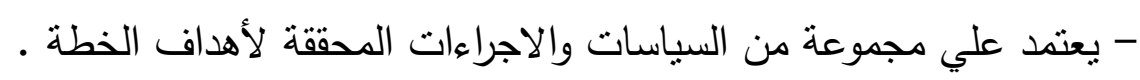

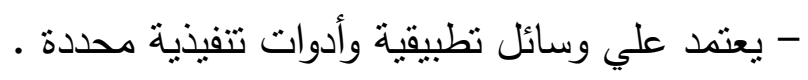

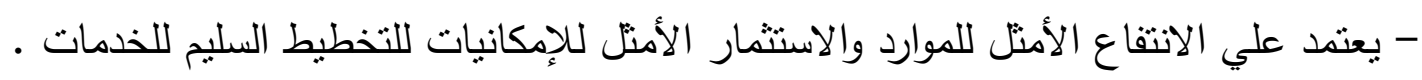

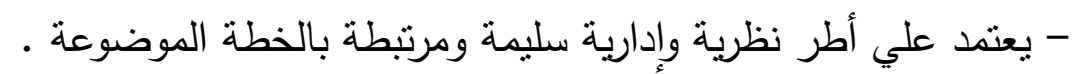

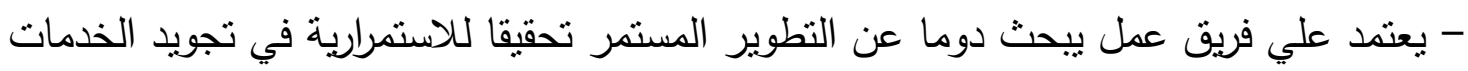

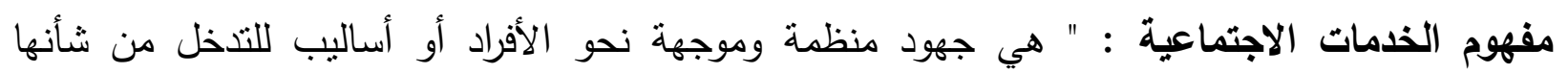

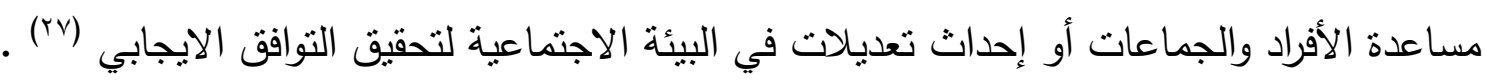

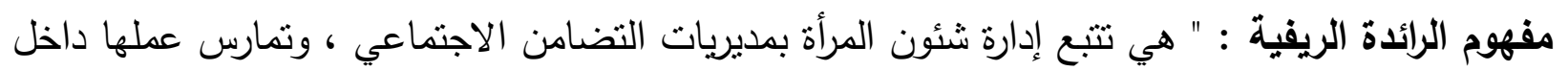

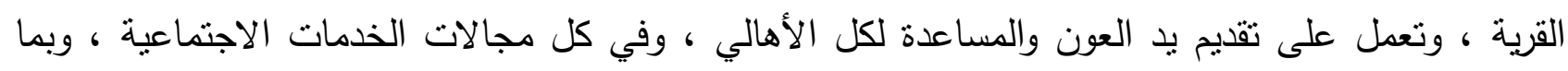

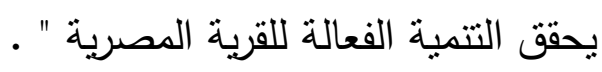


سادسا : الاجراءات المنهجية للدراسة :

- نوع الاراسة : يتحدد نوع الدراسة علي أساس أهداف الدراسة وتتنمي هذه الدراسة إلي نمط الدراسات الوصفية التحليلية . - المنهج المستخدم : استخدم الباحث منهج المسح الاجتماعي الثامل وهذا النوع يمكن من خلاله جمع المعلومات بصورة ايجابية وفعالة . - أدوات الاراسة : استخدم الباحث استمارة استبيان مطبقة علي الرائدات الريفيات بمحافظة قنا

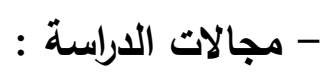
أ-المجال المكاني : محافظة قنا - مديرية التضامن الاجتماعي - الرائدات الريفيات بالمحافظة.

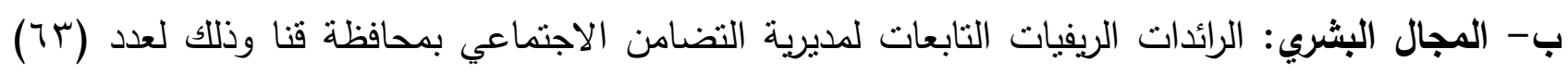
مفردة من إجمالي عدد (Y) رائدة ريفية علي مستوي محافظة قنا.

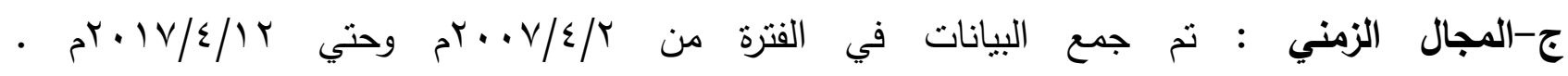


سابعاً: عرض وتحليل نتائج الار اسة الميدانية

نتائج استمارة استبيان مطبقة علي الرائدات الريفيات بمحافظة قنا

\begin{tabular}{|c|c|c|c|c|c|c|c|c|c|c|c|c|}
\hline \multicolumn{4}{|c|}{ مدة الخبرة في مجال العمل } & \multicolumn{4}{|c|}{ السن ل } & \multicolumn{4}{|c|}{ المؤهل الدراسي } & البيان \\
\hline من 10 & من & من ه إلي & & من •. & من •ـ & من •"r & & & & & & \\
\hline إلي أقل & • إإلي & أقل من & أقل من 0 & إلي أقل & إلي أقل & إلي أقل & أقل من & ليسانس/ & دبلوم فوق & ثانوية & دبلوم & البيان \\
\hline rن •r & أقل من & 1. & سنوات & من · 7 & من •0 & هن • ع & • ب سنة & بكالوريوس & المنتوسط & عامة & متوسط & الفرعي \\
\hline سنة & 0 & سنوات & & سنة & سنة & سنة & & & & & & \\
\hline 9 & 11 & $1 \leq$ & rq & r & ir & 9 & $\wedge$ & 1. & ir & 1 & $\varepsilon$. & التكرار \\
\hline$\%) \leq . \Gamma$ & $\%) \vee .0$ & \%rr.r & $\% \leq 7$ & \%or.q & $\% \backslash 9.1$ & $\%) \leqslant . \Gamma$ & $\%)$ Y.V & $\% 10.9$ & $\% 19.1$ & $\% 1.0$ & \%тr.o & النسبة \\
\hline$\varepsilon$ & r & r & 1 & 1 & r & r & $\varepsilon$ & r & r & $\varepsilon$ & 1 & الترتيب \\
\hline
\end{tabular}

يتضح من الجدول السابق ما يلي :

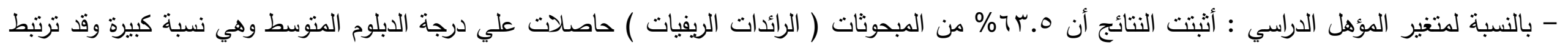

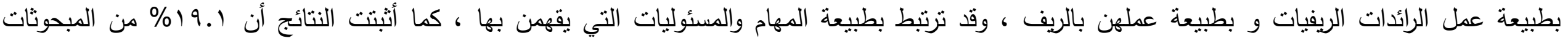

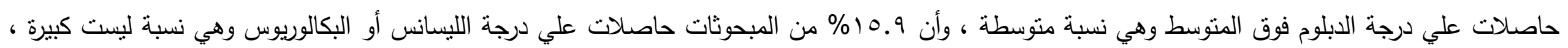
وأن 1 ـ \% من المبحوثات حاصلات علي درجة الثانوية العامة . 
- بالنسبة لمتغير السن أثتتت النتائج أن 9. 9\% من مجتمع الدراسة (الرائدات الريفيات ) في المرحلة العمرية

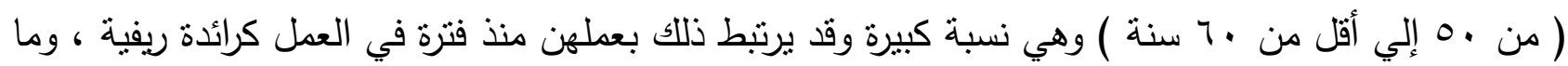

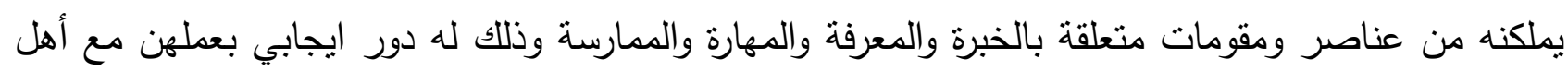

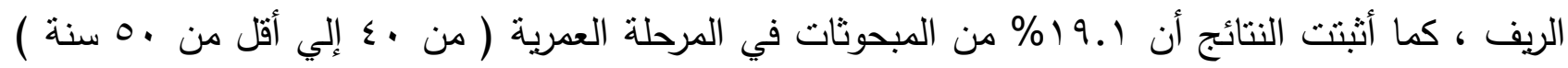

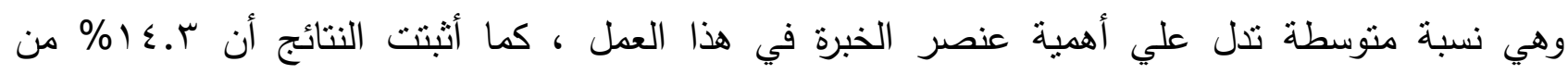

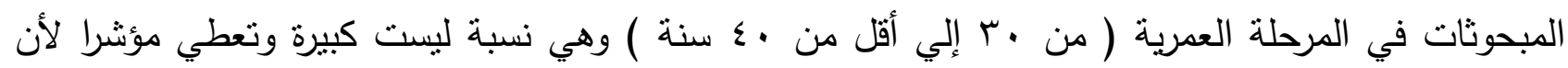

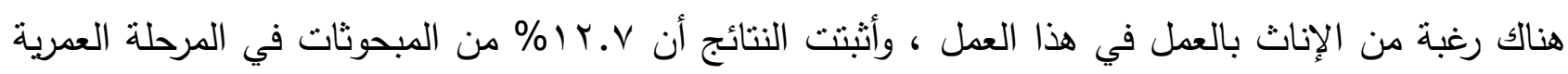

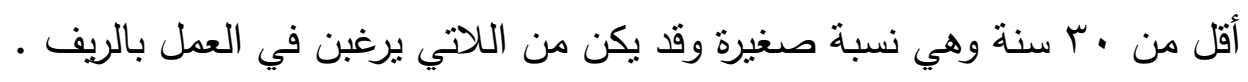

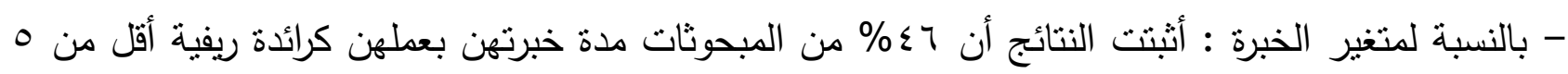

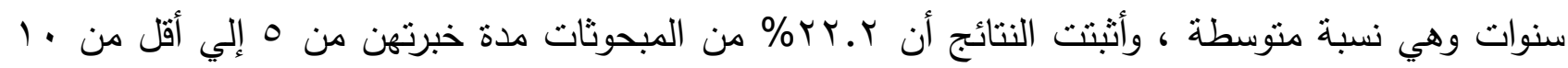

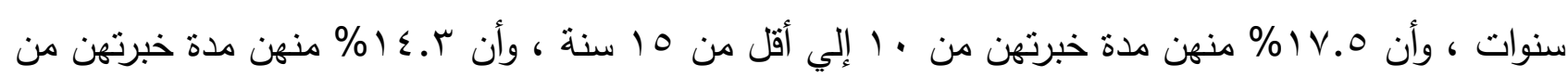

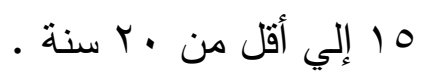
جدول رقم(r) يوضح هل هنالك خدمات اجتماعية تقدم للمر أة المسنة من خلال الر ائدات الريفيات ن = بـ

\begin{tabular}{|c|c|c|c|c|}
\hline الترتيب & $\%$ & ك & الاستجــابـــــــــة & م \\
\hline$T$ & $\varepsilon v .7$ & $r$. & نعم & أ \\
\hline $\bar{r}$ & $\mu . \wedge$ & $r$. & الي حد ما & ب ب \\
\hline \multirow[t]{2}{*}{$r$} & r. .7 & $1 r$ & V & ج \\
\hline & $\% 1 \ldots$ & $\pi$ & \multicolumn{2}{|l|}{ المجموع } \\
\hline
\end{tabular}

يتضح من الجدول السابق والذي يوضح استجابة مجتمع المبحث ( الرائدات الريفيات ) لوجود خدمات

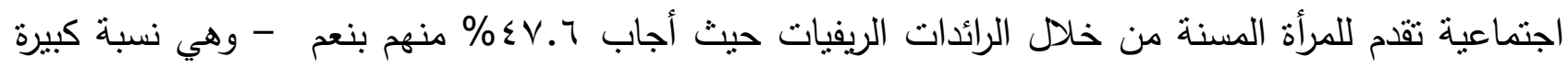

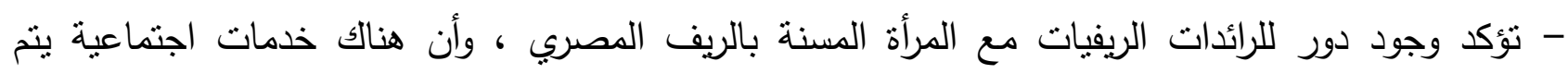

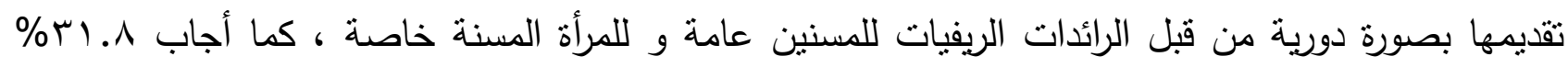
منهم بإلي حد ما - وهي نسبة ليست كبيرة - وقد يرجع ذللك إلي وجود خدمات اجتماعية ينم تقديمها للمرأة

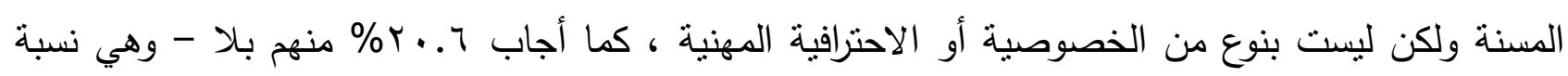

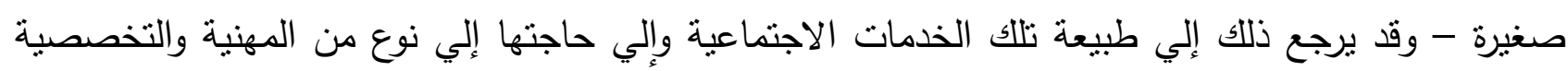

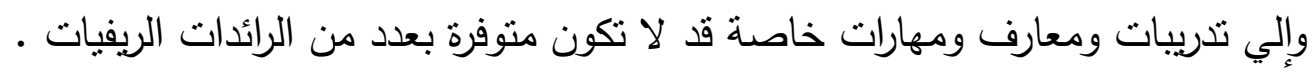


جدول رقم (ب) يوضح أهم الخدمات الاجتماعية المقدمة للمر أة المسنة ن= •

\begin{tabular}{|c|c|c|c|c|}
\hline الترتيب & $\%$ & 5] & أهم الخذمات & b \\
\hline r & or & rT & الخدمات الأسرية & i \\
\hline 0 & rA & $1 \varepsilon$ & الخدمات النفسية & ب \\
\hline$r$ & $\varepsilon \wedge$ & $r \varepsilon$ & الخدمات الغذائية & ج \\
\hline 3 & or & rT & الخدمات الدو ائية & د \\
\hline 1 & $\vee \wedge$ & rq & الخدمات العلاجية و الطبية & هـ \\
\hline V & $r \cdot$ & $1 \cdot$ & الخدمات الترويحية & 9 \\
\hline$\varepsilon$ & rᄉ & 19 & الخدمات التوعوية و الثقافية & j \\
\hline 7 & Tr & 11 & خدمات الأجهزة التعويضية المختلفة & $\tau$ \\
\hline
\end{tabular}

يتضح من الجدول السابق والذي يوضتح أهم الخدمات الاجتماعية المقدمة للمرأة المسنة من وجهة نظر الرائدات الريفيات حيث كانت كما يلي : حيث أجاب V^\% منهن بأن أهم الخدمات هي - الخدمات العلاجية والطبية ، وقد يرتبط ذلك بطبيعة المرحلة العمر للمسنات وما بحتاجونه من خدمات علاجية وطبية متنوعة ، كما أجاب ror\% منهن بأن أهم الخدمات هي - الخدمات الأسرية ، وبنفس الترتيب الخدمات الدوائية وذلك مؤشر مهم لأهم احتياجات المسنات في تلاك المرحلة من رعاية أسرية ومن خدمات دوائية مرتبطة بظروفهن المرضية والدوائية ، كما أجاب ^^؛ منهن بأن أهم الخدمات هي - الخدمات الغذائية وذلك مرتبط بطبيعة المرحلة العمرية وما يحتاجونه المسنات من أنواع محددة من الغذاء والمأكل ، كما أجاب ^r\% منهم بأن أهم الخدمات هي - الخدمات التوعوية والثقافية وهي نوعية الخدمات المرتبطة بالنواحي التوعوية والثقافية المرتبطة

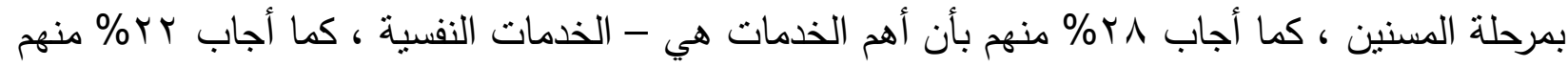
بأن أهم الخدمات هي - خدمات الأجهزة التعويضية المختلفة ، كما أجاب ، r\% منهم بأن أهم الخدمات هي الخدمات التروبحية

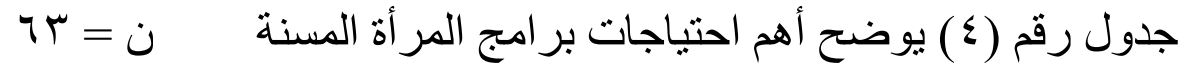

\begin{tabular}{|c|c|c|c|c|}
\hline الترتيب & $\%$ & 5] & أهم الاحتياجات & r \\
\hline 1 & $9 \cdot .0$ & ov & الحاجة إلي توفير الدخل المناسب للمر أة & أ \\
\hline r & Ar.o & or & الحاجة إلي توفير الر عاية الصحية بصور ها المختلفة & ب \\
\hline 7 & 71.9 & rq & الحاجة إلي توفير الثعور بالأمن الاجتماعي والرضاو الاشباع النفسي & ج \\
\hline $\mathrm{V}$ & $0 . .1$ & rT & الحاجة إلي توفير الاندماج و التفاعل المجتمعي و إنشباع وقت الفراغ & د \\
\hline$\Lambda$ & r^.! & $r \varepsilon$ & الحاجة إلي تحقيق التكيف ومو اجهة ضغوط وتحديات الحياة المختلفة & هـ \\
\hline r & 79.1 & $\varepsilon \varepsilon$ & الحاجة غلي توفير عدم الشعور بالعزلة والشعور بالأهمية الاجتماعية & 9 \\
\hline 0 & $7 \% .0$ & $\varepsilon \cdot$ & الحاجة إلي توفير التثقيف الدوائي والعلاجي لاحتياجات المر أة المسنة & j \\
\hline$\varepsilon$ & 77. $\mathrm{V}$ & $\varepsilon r$ & الحاجة إلي تطوير بر امج المر أة المسنة بما يلائم احتياجاتهن الفعلية & $\tau$ \\
\hline
\end{tabular}


يتضح من الجدول السابق والذي يوضتح أهم احتياجات المرأة المسنة من وجهة نظر المبحوثات حيث كانت كما يلي : يث أجاب 0. •9\% منهن بأن أهم الاحتباجات هي - الحاجة إلي توفير الدخل المناسب للمرأة ، وهي نسبة مرتفعة تؤكد أهمية توفير الموارد المالية لمرأة المسنة وتؤكد حاجتها إلي توفير الدعم المالي لهن

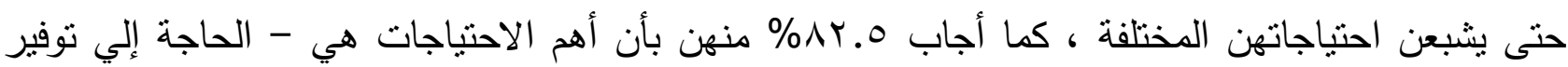
الرعاية الصحية بصورها المختلفة ، وهي نسبة مرتفعة تشير إلي أهمية توفير الرعاية الصحية للمسنات وذللك لما بالمرحلة العمرية للمسنات من احتياجات هامة مرتبطة بالبعد الصحي ، كما أجاب ^.97\% منهن بأن أهم الاحتياجات هي - الحاجة إلي توفير عدم الثعور بالعزلة والثعور بالأهمية الاجتماعية ، وهي نسبة كبيرة تشير إلي أهمية البعد الاجتماعي وأهمية اثنباع الاحتياجات الاجتماعية للمسنات ، كما أجاب V.77\% منهن بأن أهم الاحتياجات هي - الحاجة إلي تطوبر برامج المرأة المسنة بما بلائمهم احتباجاتهن الفعلية ، وهي نسبة معقولة تشير إلي حاجة المسنات إلي برامج تشبع احتياجاتهن ، و تشير إلي السعي إلي تطويرها بما بتتاسب مع احتياجات ومتغيرات العصر، كما أجاب ه.ب7\% منهن بأن أهم الاحتياجات هي - الحاجة إلي توفير التتقيف الدوائي والعلاجي لاحتياجات المرأة المسنة ، وهي معقولة ترتبط بحاجة المسنات إلي التتقيف الدوائي والعلاجي المختلفة ، كما أجاب 9. (آ\% منهن بأن أهم الاحتياجات هي - الحاجة إلي توفير الثعور بالأمن الاجتماعي والرضا والاشباع النفسي ، وهي نسبة معقولة نتير إلي حاجة المسنات إلي الأمن الاجتماعي والرضا النفسي ، كما أجاب ^.. •ه\% منهن بأن أهم الاحتياجات هي - الحاجة إلي توفير الاندماج والتفاعل المجتمعي واشباع

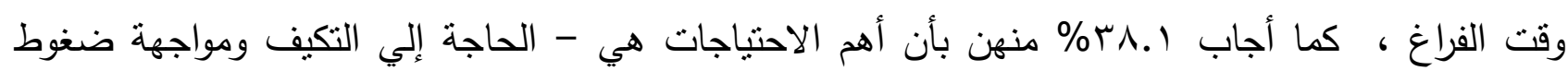
وتحديات الحياة المختلفة .

جدول رقم (0) يوضح أهم البرامج التي يمكن للر ائدات الريفيات أن تقدمها للمر أة المسنة ن =س

\begin{tabular}{|c|c|c|c|c|c|c|c|c|}
\hline التزتيب & المرجحة & المترجط & المجموعة & موافير & إلي حوافما & 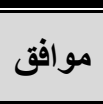 & أهم البرامج & م \\
\hline 1 & $\% q 4 . V$ & $Y . \wedge 1$ & IVV & r & $\Lambda$ & or & برامج الزيارات المنزلية للمسنين في المنازل & أ \\
\hline 7 & $\% 9 \cdot .0$ & r.VI & $1 V 1$ & $r$ & ir & $\varepsilon \wedge$ & برامج الندوات الثقافة الصحية للمسنين & ب \\
\hline 0 & $\% 91$ & Y.VT & IVY & 1 & 10 & $\leqslant V$ & برامج التظذية السليمة للمسنين & ج \\
\hline$r$ & $\% 94.7$ & 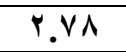 & IVo & $r$ & $\wedge$ & Or & برامج الرعاية الصحية المتكاملة للمسنين & د \\
\hline$\Lambda$ & 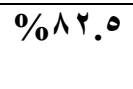 & Y.\&V & 107 & r & rq & ru & برامجين الرعاية الاجتماعية الترفيهية & هـ \\
\hline$r$ & $\% 9$ \%.1 & Y.V & IV & 1 & ir & $\leqslant 9$ & برامج التثقيف الدوائي والعلاجي للمسنين & و \\
\hline$\varepsilon$ & $\% 91.0$ & 1.10 & IVr & $r$ & ir & $\leq 9$ & 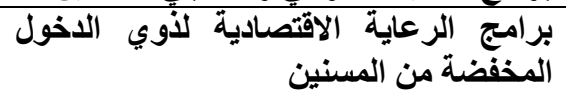 & j \\
\hline$\rho^{\Lambda}$ & $\%$ \%^.。 & Y.¿V & 109 & 0 & rT & ro & برامج اشباع وقت الفراغ & $\tau$ \\
\hline 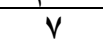 & $\% \wedge \uparrow . \uparrow$ & r.01 & 101 & 7 & 19 & $r \wedge$ & برامج الاعداد والتأهيل لتقاعد كبار السن & b \\
\hline \multicolumn{7}{|c|}{$101 Y$} & \multicolumn{2}{|l|}{ المجموع } \\
\hline \multicolumn{7}{|c|}{ Y.TV } & \multicolumn{2}{|l|}{ المتوسط الحسابي المرجح } \\
\hline \multicolumn{7}{|c|}{$\% \wedge \wedge . q$} & \multicolumn{2}{|l|}{ القوة النسبية } \\
\hline
\end{tabular}


يتضح من الجدول السابق والذي يوضتح أهم البرامج التي يمكن للرائدة الريفية أن تقدمها للمرأة المسنة مرتبة حسب الاوزان المرجحة حيث كانت كما يلي : برامج الزيارات المنزلية للمسنين في المنازل ، وذللك بنسبة مرجحة

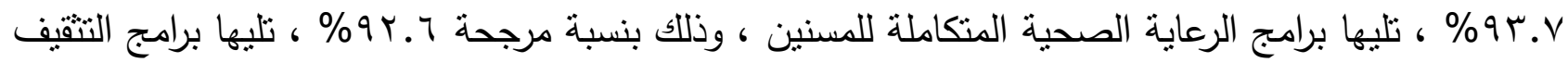
الدوائي والعلاجي للمسنين ، وذللك بنسبة مرجحة ا.ج\%\% ، تليها برامج الرعاية الاقتصادية لذوي الدخول المنخفضة من المسنين ، وذلك بنسبة مرجحة 0. 1) ، ثليها برامج التغذية السليمة للمسنين ، وذلك بنسبة مرجحة ا9\% ، تليها برامج الندوات النشر الثقافة الصحية للمسنين ، وذلك بنسبة مرجحة 0 \% \% ، نليها برامج الاعداد والتأهيل التقاعد كبار السن ، وذلك بنسبة مرجحة ج.ب^\% ، تليها برامج الرعاية الاجتماعية الترفيهية

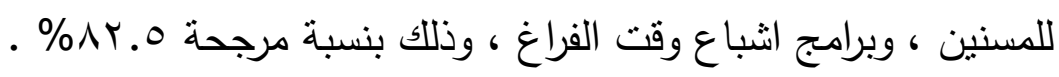

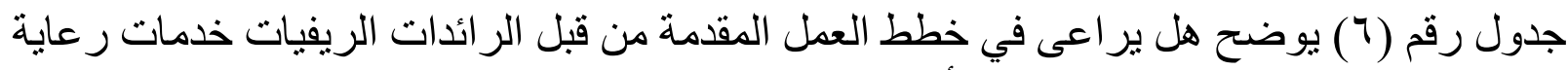
المراة المسنة

\begin{tabular}{|c|c|c|c|c|}
\hline الترتيب & $\%$ & ك & 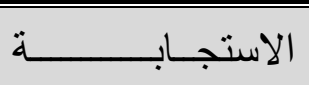 & b \\
\hline 1 & $\% 0 \leq$ & $\Gamma \varepsilon$ & نعم & أ \\
\hline r & \% \% & YI & الي حد ما & ب \\
\hline \multirow[t]{2}{*}{$r$} & $\%$ \%.Y & $\wedge$ & $y$ & ج \\
\hline & $\% 1 \ldots$ & 74 & \multicolumn{2}{|l|}{ المجموع } \\
\hline
\end{tabular}

يتضح من الجدول السابق والذي يوضح وجهة نظر الرائدات الريفيات لمراعاة خطط العمل المقدمة منهن لخدمات رعاية المرأة المسنة حيث أجاب ؟0\% منهن بنعم - وهي نسبة معقولة نتبر إلي وجود خطط منتوعة لرعاية المرأة المسنة من قبل الرائدات الريفيات ، كما أجاب س.بr\% منهن بإلي حد ما - وقد يرجع ذلك إلي وجود خدمات تقدم من قبل الرائدات الريفيات لرعاية المرأة المسنة ولكنها ليست بالصورة المرجوة ، كما أجاب V. I I منهن بلا - وهي نسبة ضعيفة ، ولكن تعطي مؤثر هام بضرورة الاهتمام بوضع خطط محددة لعمل الرائدات الريفيات لتقديمها لرعاية المرأة المسنة . 


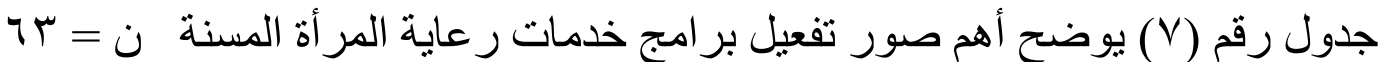

\begin{tabular}{|c|c|c|c|c|c|c|c|c|}
\hline الترتيب & المرجبة & المتوسط & ال الأوزان & 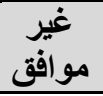 & إلي حوافقي & موافق & أهم صور تفعيل برامج خدمات رعاية المرأة & p \\
\hline 7 & $\% \wedge$ \% . & ץ. . & $17 \varepsilon$ & - & ro & $r \Lambda$ & تفريل المسياسـات التشريعية المهتمة بقضايا & أ \\
\hline$\varepsilon$ & $\% \wedge \wedge . \wedge$ & Y.7r & 177 & 1 & ri & $\leqslant 1$ & التبيؤ السليم بمشادل التول المرأة المسنة والعمل & ب \\
\hline r & $\% \wedge 9 .\{$ & ५. ४ & 179 & r & 17 & $\leq 0$ & 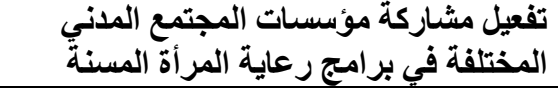 & ج \\
\hline 0 & $\%^{\wedge \vee} .^{\top}$ & Y.TY & 170 & $r$ & 11 & $\varepsilon r$ & 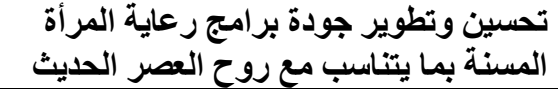 & $د$ \\
\hline$\Lambda$ & $\% \vee \vee \wedge . r$ & Y.TO & $1 \leqslant 1$ & $\mathrm{~V}$ & YV & rq & 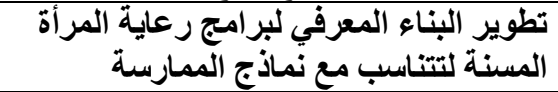 & هـ \\
\hline 1 & $\% q \leq . r$ & $r . \wedge r$ & $I V A$ & - & 11 & or & رفح كفاءة مستوي العاملين بيرامج رعاية & و \\
\hline V & $\%^{\wedge} \leqslant . \vee$ & Y.0 & 17. & 0 & 19 & rq & 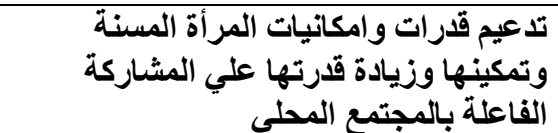 & j \\
\hline$r$ & $\% \wedge \wedge . \varepsilon$ & Y.70 & 178 & $r$ & 17 & « & 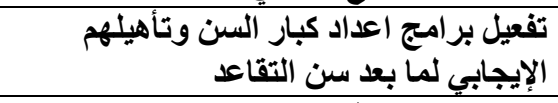 & $\tau$ \\
\hline \multicolumn{7}{|c|}{ ITIV } & \multicolumn{2}{|l|}{ المجموع } \\
\hline \multicolumn{7}{|c|}{$r .71$} & \multicolumn{2}{|l|}{ المتوسط الحسابي المرجح } \\
\hline \multicolumn{7}{|c|}{$\% \wedge \vee .1$} & \multicolumn{2}{|l|}{ القوة النسبية } \\
\hline
\end{tabular}

يتضح من الجدول السابق الذي يوضح أهم صور تفعيل برامج خدمات رعاية المرأة المسنة من قبل الرائدات الريفيات مرتبة حسب الأوزان المرجحة حيث كانت كما يلي : رفع كفاءة مستوي العاملين ببرامج رعاية المرأة المسنة ، وذللك بنسبة مرجحة r. 9\% ، تليها تفعيل مشاركة مؤسسات المجتمع المدني المختلفة في برامج رعاية المرأة المسنة ، وذلك بنسبة مرجحة ـ. 9.\% ، تليها تفعيل برامج إعداد كبار السن وتأهيلهم الايجابي لما

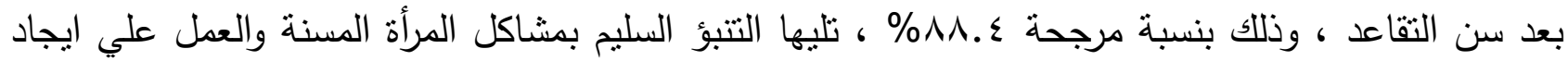
حلول واقعية لها ، وذللك بنسبة مرجحة ^.^v. ، نليها تحسين وتطوير جودة برامج رعاية المرأة المسنة بما يتتاسب مع روح العصر الحديث ، وذلك بنسبة مرجحة r.NV.\% ، تليها تفعيل السياسات التشريعية المهتمة بقضايا المرأة المسنة ، وذلك بنسبة مرجحة 7.>>\% ، تلايها تدعيم محددات وامكانيات المرأة المسنة وتمكينها

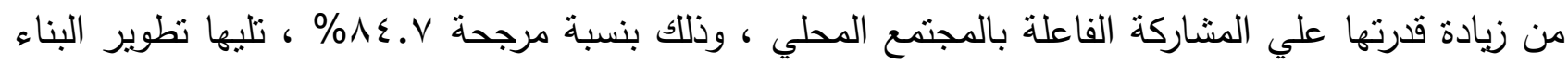
المعرفي لبرامج رعاية المرأة المسنة لتتناسب مع نماذج الممارسة ، وذلك بنسبة درجحة ب. \%VA. . 


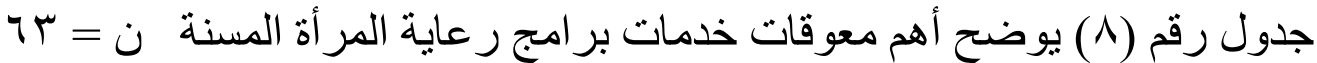

\begin{tabular}{|c|c|c|c|c|c|c|c|c|}
\hline الترتيب & المرجبة & المترجط المترج & 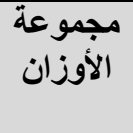 & 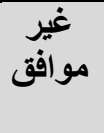 & موالئ & موافق & أهم معوقات خدمات برامج رعاية المرأة & b \\
\hline 0 & $\% \wedge$ \%४^ & Y.71 & $17 \varepsilon$ & - & ro & rی & 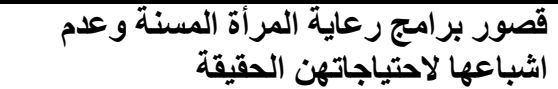 & i \\
\hline$r$ & $\%$ \% . . & Y.VT & IV & - & 10 & $\varepsilon \wedge$ & قلة اعداد المؤسسنة المساتة المتماعية العاملة في & ب \\
\hline$\varepsilon$ & $\% \wedge \vee . \vee$ & Y.7Y & 170 & $\varepsilon$ & 17 & $\varepsilon r$ & 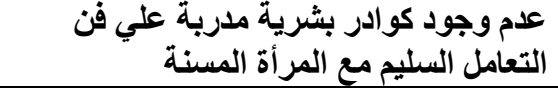 & ج \\
\hline$r$ & $\% \wedge \wedge . \varepsilon$ & r.70 & $17 \mathrm{~V}$ & 0 & ir & $\leqslant \uparrow$ & بصفة توامة والمر معلوة المسنة بليمفة عن المسنين & د \\
\hline pr & $\%$ \%१.। & Y.VT & $I V \varepsilon$ & $r$ & 9 & 01 & 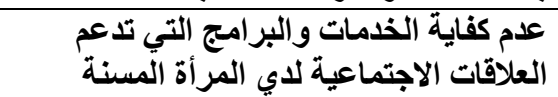 & هـ \\
\hline 1 & $\% 9 \leq . Y$ & $r . \wedge r$ & $I V A$ & $r$ & 0 & 00 & 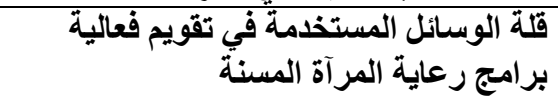 & 9 \\
\hline \multicolumn{7}{|c|}{$\begin{array}{l}1 \cdot Y r \\
\end{array}$} & \multicolumn{2}{|l|}{ المجموع المج } \\
\hline \multicolumn{7}{|c|}{ Y.V } & \multicolumn{2}{|l|}{ المتوسط الحسابي المرجح } \\
\hline \multicolumn{7}{|c|}{$\% 91.1$} & \multicolumn{2}{|l|}{ القوة النسبية } \\
\hline
\end{tabular}

يتضح من الجدول السابق والذي يوضح - أهم معوقات خدمات برامج رعاية المرأة المسنة من وجهة نظر الرائدة الريفيات مرتبة حسب الأوزان المرجحة حيث كانت كما يلي : قلة الوسائل المستخدمة في تقديم فعالية برامج رعاية المرأة المسنة ، وذلك بنسبة مرجحة ب.ء9\% ، تليها قلة أعداد المؤسسات الاجتماعية العاملة في مجال المرأة المسنة ، وعدم كفاية الخدمات والبرامج التي تدعم العلاقات الاجتماعية لدي المرأة المسنة ، وذللك بنسبة مرجحة 1. 9\% ، تليها عدم توافر نظم معلومات سليمة عن المسنين بصفة عامة والمرأة المسنة بصفة خاصة ، وذلك بنسبة مرجحة ع^^^\% ، تلايها عدم وجود كوادر بشرية مدربة علي فن التعامل السليم مع المرأة المسنة ، وذلك بنسبة مرجحة r.^v\% ، ثليها قصور برامج رعاية المرأة المسنة وعدم اشباعها لاحتياجاتهن

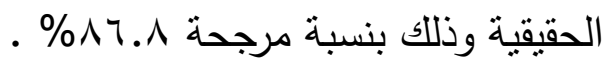


جدول رقم (9) يوضح أهم مقترحات تطوير خطط عمل الر ائدات الريفيات في مجال رعاية المرأة

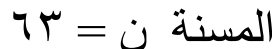

\begin{tabular}{|c|c|c|c|c|c|c|c|c|}
\hline الترتيب & المرجبة النسبة & المتوسط المرجع & مجموعة & موافيز & إلى موافى حدما & 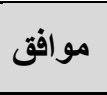 & أهم مقترحات تطوير خطط عمل الرية الرائدات المرات المسنة & b \\
\hline r & $\% 9 \varepsilon . Y$ & Y.Ar & $1 \vee \wedge$ & 1 & 9 & or & تصميم نماذج مهنية متطورة لحماية المسنين & أ \\
\hline $\mathrm{V}$ & $\% \wedge 9 . \varepsilon$ & $Y .71$ & 179 & - & r. & $\varepsilon r$ & زبالعمل مع المر أة المسنة المسية الاجتماعية المهتمة & ب \\
\hline 7 & $\% 91$ & Y.VT & IVY & - & $1 \leq$ & $\varepsilon \wedge$ & 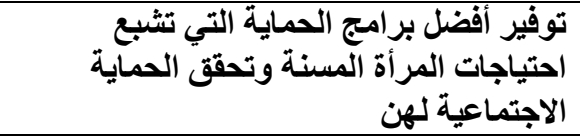 & ج \\
\hline$\Lambda$ & $\% \wedge \vee . r$ & Y.TY & 170 & $r$ & $r \cdot$ & $\leq 1$ & 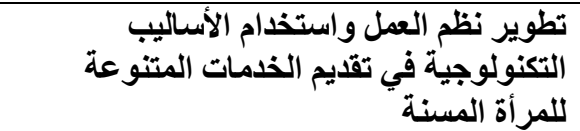 & د \\
\hline bl & $\% \wedge 9 . \varepsilon$ & $r .71$ & 199 & r & 17 & $\leqslant 0$ & تطوير عمل الممارس المهني ليمارس دوره & هـ \\
\hline 0 & $\% 91.0$ & Y.VO & IVY & r & ir & $\varepsilon 9$ & في مجال رياسية المرأة المسنة عمل الرائدات الريفيات & و \\
\hline$a^{r}$ & $\% 9 \leq . Y$ & $r . \wedge r$ & $1 \vee \wedge$ & - & 11 & or & تلزويد الرائدات الريفيات بالمهارات التخطيطية المعلة المسنة & j \\
\hline$\varepsilon$ & $\% 9$ Y. 1 & $Y . V Y$ & $1 V \varepsilon$ & $r$ & 9 & 01 & تفيمويل دور الرائدات الريفيات بأندية المسنين & $\tau$ \\
\hline$r$ & $\% 9 r . V$ & Y.AI & IVV & 1 & 1 . & or & 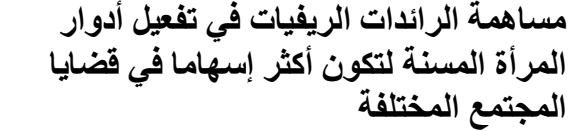 & b \\
\hline 1 & $\% 97 . r$ & $Y . \wedge q$ & INY & - & $V$ & 07 & تطوير البرامج التدريبية المؤهلة لعمل & ي \\
\hline \multicolumn{7}{|c|}{ IVHV } & \multicolumn{2}{|l|}{ المجموع المع } \\
\hline \multicolumn{7}{|c|}{ Y.VY } & \multirow{2}{*}{\multicolumn{2}{|c|}{ المتوسط الحسابي المرجح }} \\
\hline \multicolumn{7}{|c|}{$\% 91.9$} & & القوة النسبية \\
\hline
\end{tabular}

يتضح الجدول السابق والذي يوضح أهم مقترحات تطوير خطط عمل الرائدات الريفيات في مجال رعاية المرأة المسنة مرنبة حسب الأوزان المرجحة حيث كانت كما يلي : تطوير البرامج التدريبية المؤهلة لعمل الرائدات

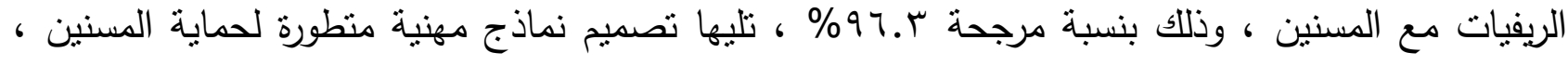

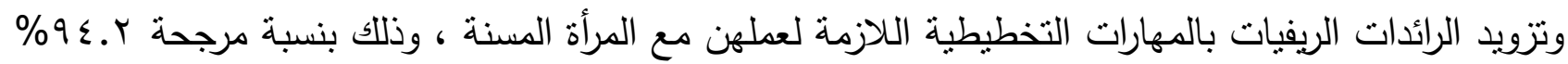

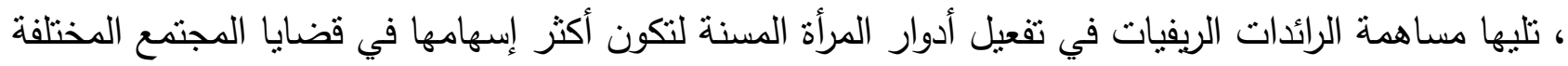

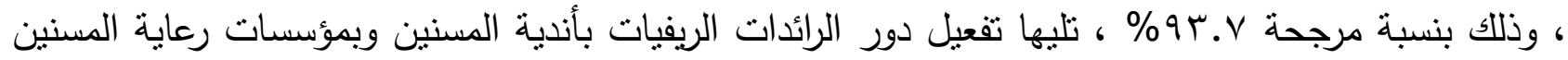
وذلك بنسبة مرجحة و.9\%\% ، تليها نطوير سياسات وخطط عمل الرائدات الريفيات في مجال رعاية المرأة المسنة وذلك بنسبة مرجحة ه.91\% ، تلايها توفير أفضل برامج الحماية التي تشبع احتياجات المرأة المسنة وتحقق الحماية الاجتماعية لهن ، وذلك بنسبة مرجحة (9\% ، تليها زيادة فاعلية المؤسسات الاجتماعية المهتمة بالعمل مع المرأة المسنة ، وتطوير عمل الممارس المهني ليمارس دورة بفاعلية في مجال المسنين ، وذللك بنسبة 
مرجحة ع. 9^\% ، تليها تطوبر نظم العمل واستخدام الأساليب التكنولوجية في تقديم الخدمات المتتوعة للمرأة

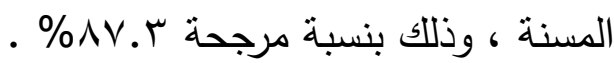

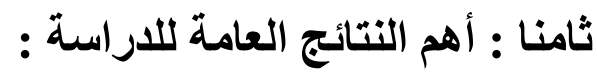

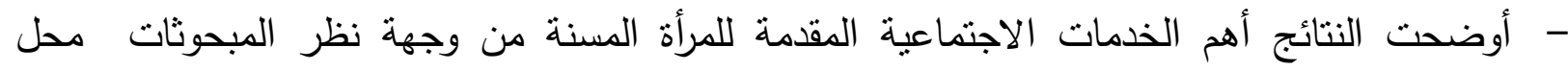
الدراسة ( الرائدات الريفيات ) هي : الخدمات العلاجية والطبية بنسبة \%^ \% ، والخدمات الأسرية ،

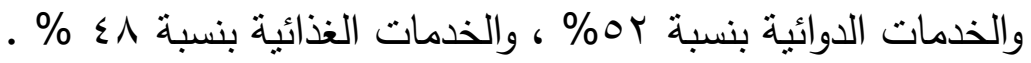
- أوضحت النتائج أهم احتياجات برامج المرأة المسنة من وجهة نظر المبحوثات محل الدراسة ( الرائدات الريفيات ) هي : الحاجة إلي توفير الاخل المناسب للمرأة بنسبة هـ ـ ٪ ، والحاجة إلي توفير الرعاية الصحية بصورها المختلفة بنسبة ه.NY\% ، والحاجة إلي توفير عدم الثعور بالعزلة والثعور بالأهمية الاجتماعية بنسبة 19.1979 - - أوضحت النتائج أهم البرامج التي يمكن للرائدات الريفيات أن تقدمها للمرأة المسنة مرتبة حسب الأوزان المرجحة هي : برامج الزيارة المنزلية للمسنين في المنازل بنسبة V.rو\% ، وبرامج الرعاية الصحية

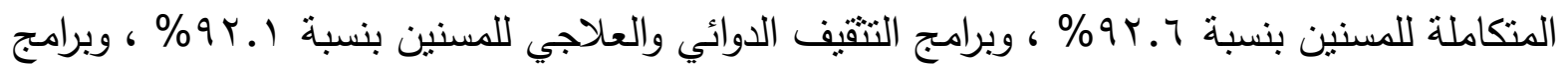
الرعاية الاقتصادية لذوي الدخول المنخفضة من المسنين بنسبة 0. 91 \% .

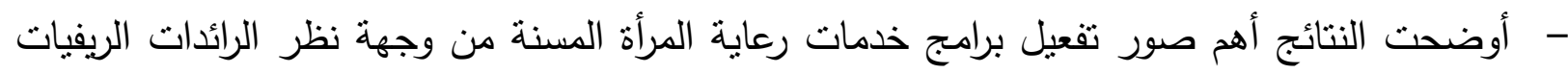
مرتبة حسب الأوزان المرجحة هي : رفع كفاءة مستوى العاملين ببرامج رعاية المرأة المسنة بنسبة

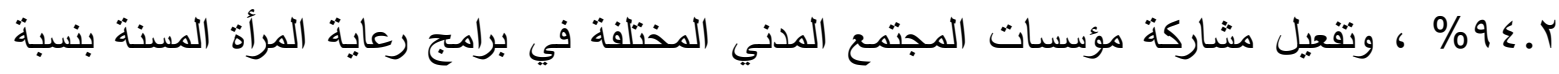

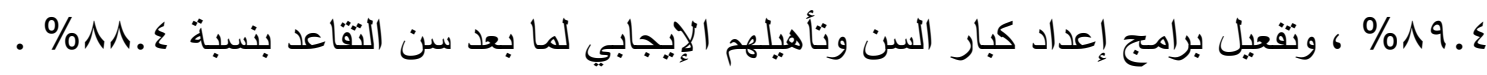
- - أوضحت النتائج أهم معوقات خدمات برامج رعاية المرأة المسنة من وجهة نظر الرائدات الريفيات مرنبة حسب الأوزان المرجحة هي : قلة الوسائل المستخدمة في تقويم فعالية برامج رعاية المرأة المسنة بنسبة r.ء 9\% ، وقلة أعداد المؤسسات الاجتماعية العاملة في مجال المرأة المسنة ، وعدم كفاية الخدمات والبرامج التي تدعم العلاقات الاجتماعية لدى المرأة المسنة بنسبة ا. ـr9\% . - - أوضحت النتائج أهم مقترحات تطوير خطط عمل الرائدات الريفيات في مجال رعاية المرأة المسنة من وجهة نظر الرائدات الريفيات مرتبة حسب الأوزان المرجحة هي : تطوير البرامج التدربيية المؤهلة لعمل الرائدات الريفيات مع المسنين بنسبة ؟.79\% ، وتصميم نماذج مهنية منطورة لحماية المسنين ، وتزويد الرائدات الريفيات بالمهارات التخطيطية اللازمة لعملهن مع المرأة المسنة بنسبة. .؟ 9\% ، ومساهمة الرائدات الريفيات في تفعيل أدوار المرأة المسنة لتكون أكثر اسهاما في قضايا المجتمع المختلفة بنسبة 


\section{تاسعا : نموذج تخطيطي لتعامل الرائدات الريفيات مع الخدمات الاجتماعية المقدمة للمرأة المسنة :}

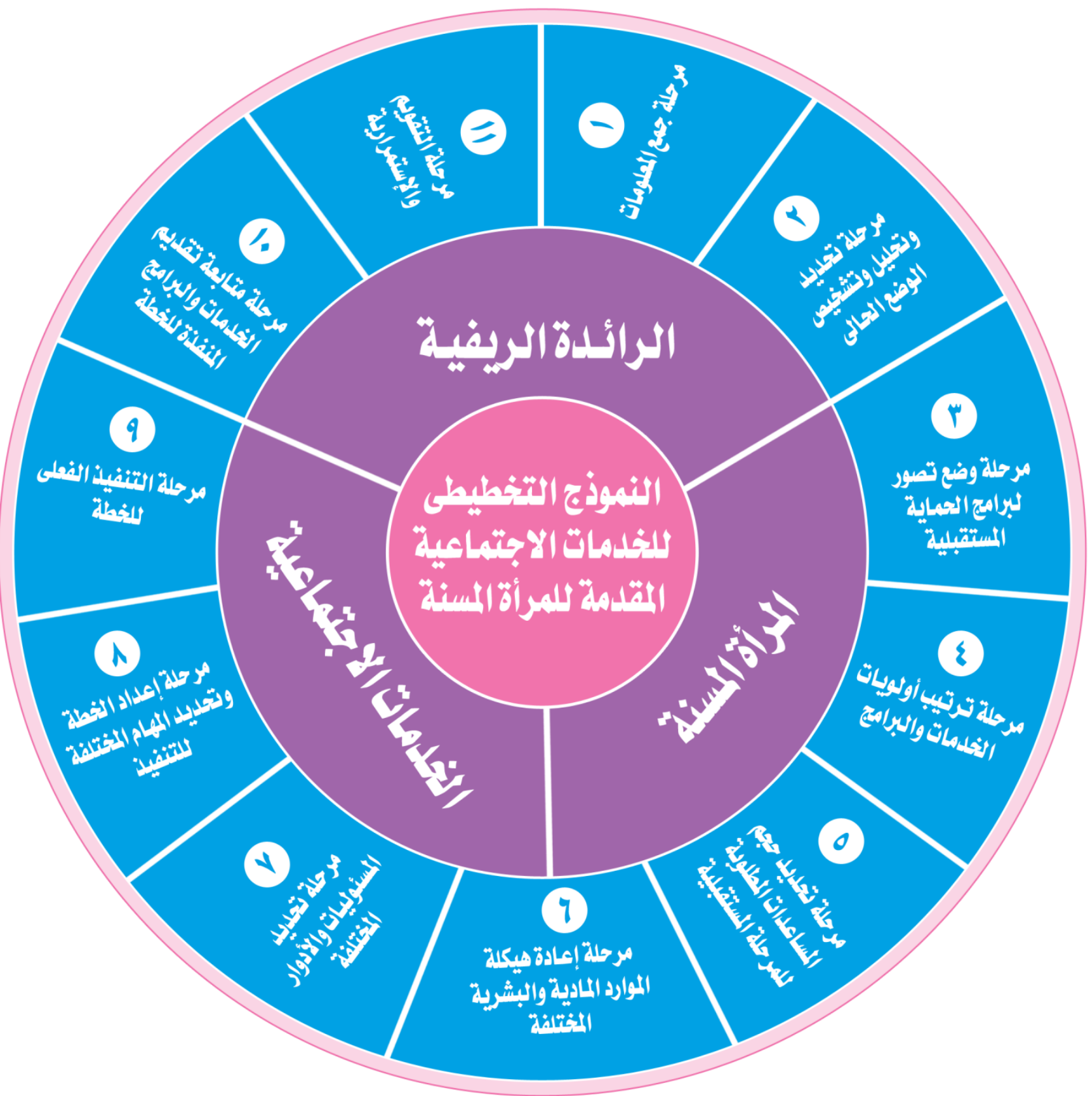


هذا ويتكون النموذج التخطيطي لتعامل الرائدات الريفيات مع الخدمات الاجتماعية المقدمة للمرأة المسنة من المراحل التالية : 20 - من

1 - مرحلة جمع المعلومات والتحديد الدقيق لمجتمع العمل تمهيدا لإعداد الخطة المقترحة . r- مرحلة تحديد وتحليل وتشخيص الوضع الحالي للخدمات والبرامج المقدمة للمرأة المسنة . r- مرحلة وضع تصور لبرامج الحماية المستقبلية للمرأة المسنة .

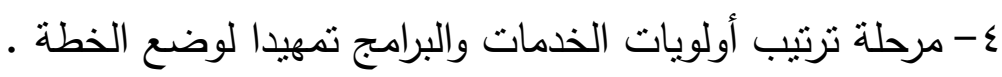

ه- مرحلة تحديد حجم المساعدات المطلوبة للمرحلة المستقبلية . ج- مرحلة إعادة هيكلة الموارد المادية والبشرية المتاحة بالمجتمع المحلي . - مرحلة تحديد المسئوليات والأدوار المختلفة للمشاركة في تتفيذ الخطة . - مرحلة إعداد الخطة وتحديد المهام المختلفة للتفيذ . ماته 9- مرحلة التنفيذ الفعلي للخطة .

• - مرحلة متابعة تقديم الخدمات والبرامج المنفذة بالخطة . 11- مرحلة التقويم والاستمرارية . وتثمثل أهم الأدوار المهنية الممارسة في الآتي : ا - دوره في دراسة وتحديد الواقع المجتمعي • r- دوره في تحليل وتشخيص الواقع الحالي للمرأة المسنة . ب- دوره في تحديد أولويات الخدمات والبرامج المقدمة للمرأة المسنة . ؟ - دوره كمخطط لخدمات المرأة المسنة . - دوره كمنسق للخدمات المقدمة للمرأة المسنة . 7 - دوره كجامع للبيانات والمعلومات . - دوره كمستثير لتفعيل استخدام الموارد المتاحة . -V • -

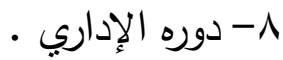

1 1 - دوره التسويقي للخدمات والبرامج المقدمة للمرأة المسنة . r ا - دوره في وضع الخدمات والبرامج المشبعة لاحتياجات المرأة المسنة . r ا - دوره كمنفذ للخدمات والبرامج المقدمة للمرأة المسنة . ع ا - دوره في متابعة الخدمات والبرامج المقدمة للمرأة المسنة . 10- دوره في تقوبم الخدمات والبرامج المقدمة للمرأة المسنة . 7 ا - دوره في الارتقاء والتجويد بمستوى الخدمات المقدمة للمرأة المسنة تحقيقا للاستمرارية . 
تصور تحليلي تطبيقي لمتطلبات استخدام النموذج التخطيطي لتعامل الرائدات الريفيات مع الخدمة الاجتماعية المقدمة للمرأة المسنة

\begin{tabular}{|c|c|c|c|c|}
\hline الأدوار المهنية المتوقعة & منهجية وخطوات العمل المتبعة & الشروط والمراحل المطلوية & الأهداف المرحلية & مراحل النموذج التخطيطي \\
\hline 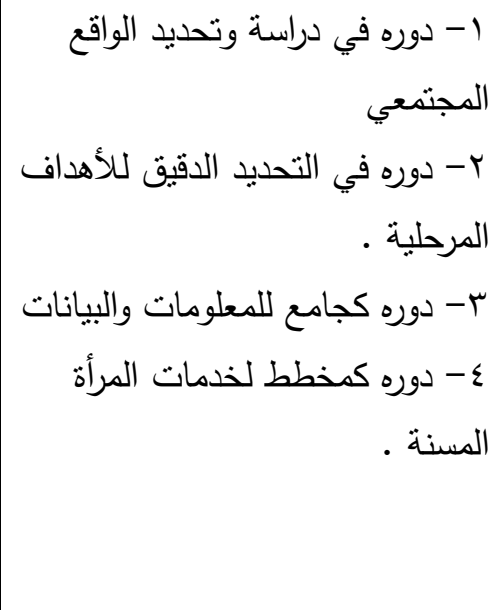 & 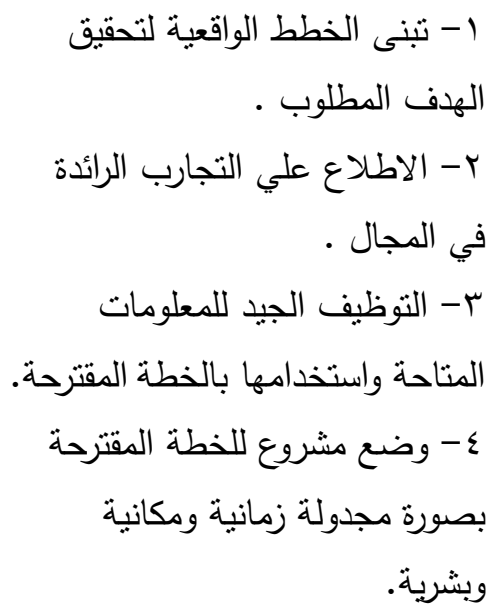 & 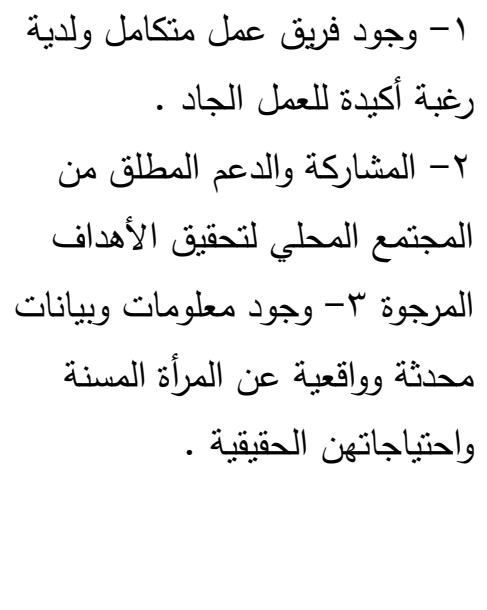 & 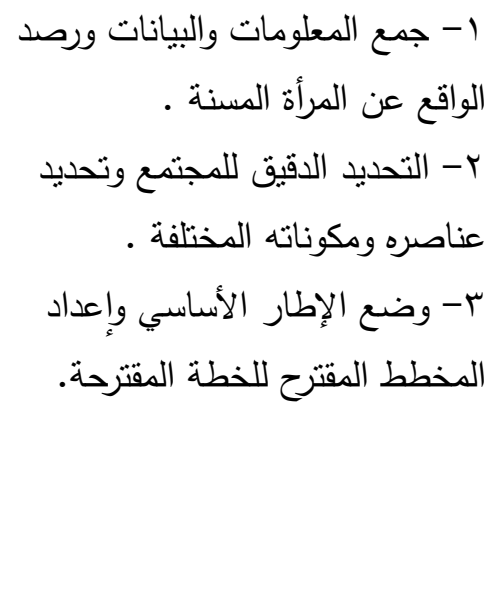 & 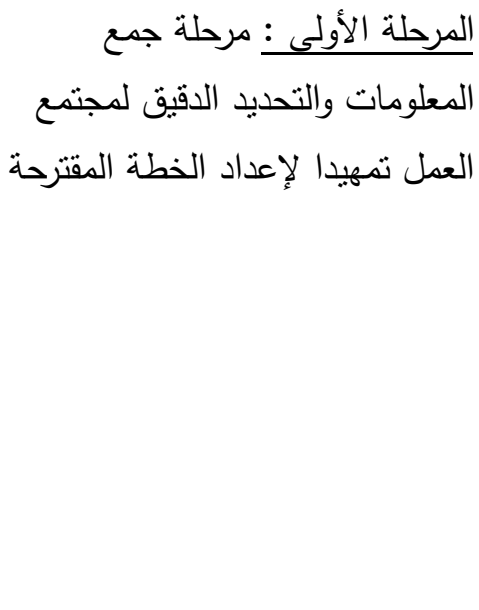 \\
\hline 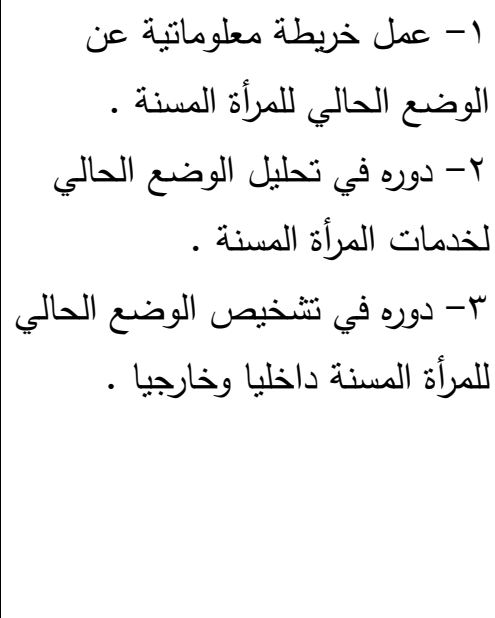 & 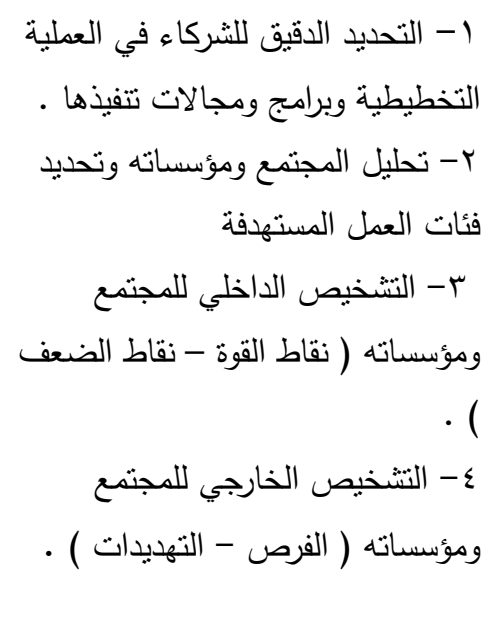 & 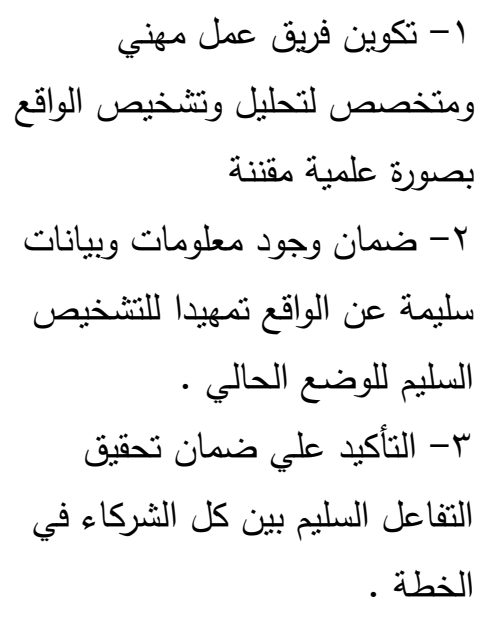 & 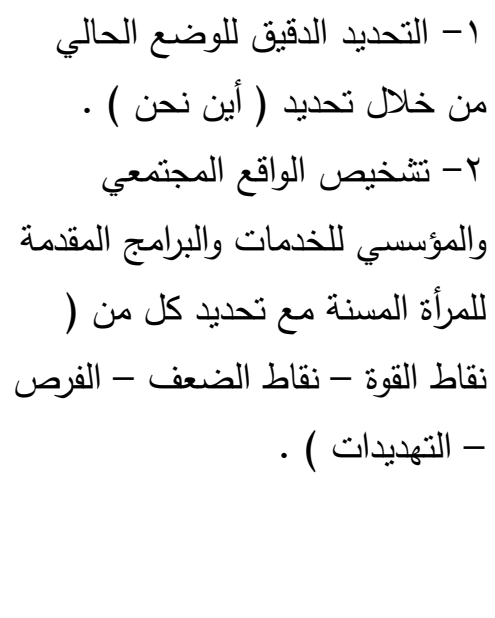 & 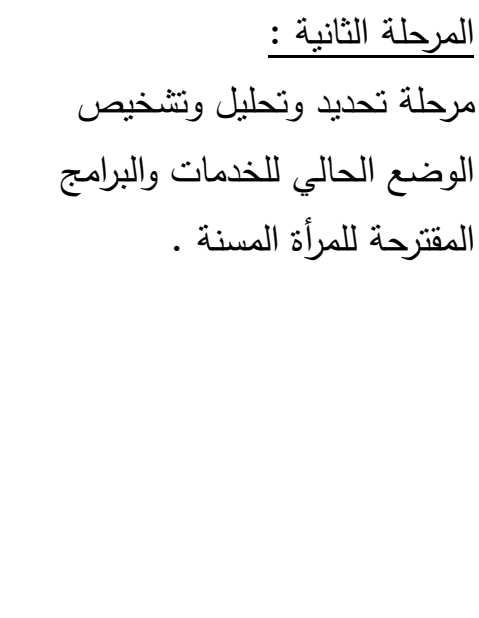 \\
\hline
\end{tabular}




\begin{tabular}{|c|c|c|c|c|}
\hline ז 1 - دوره كخبير • دوره كخطط r- دوره كمحلل. & 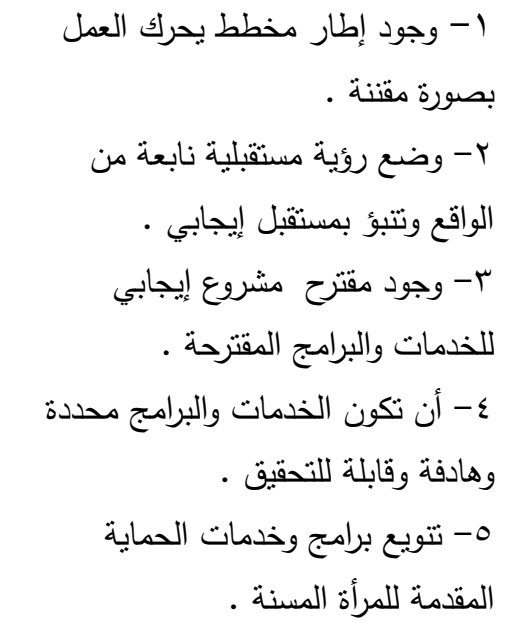 & 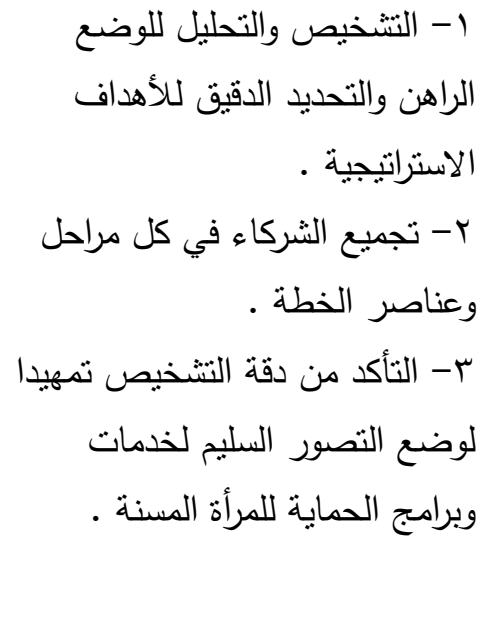 & 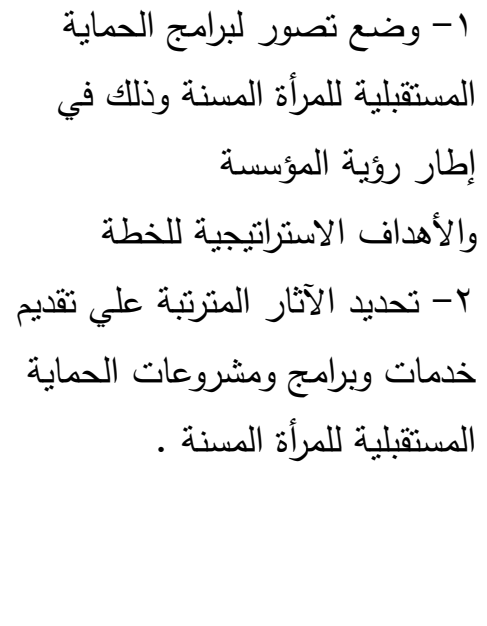 & البرامج الحماية المستقبلة الثالثة : مرحلة وضع تلمرأة \\
\hline 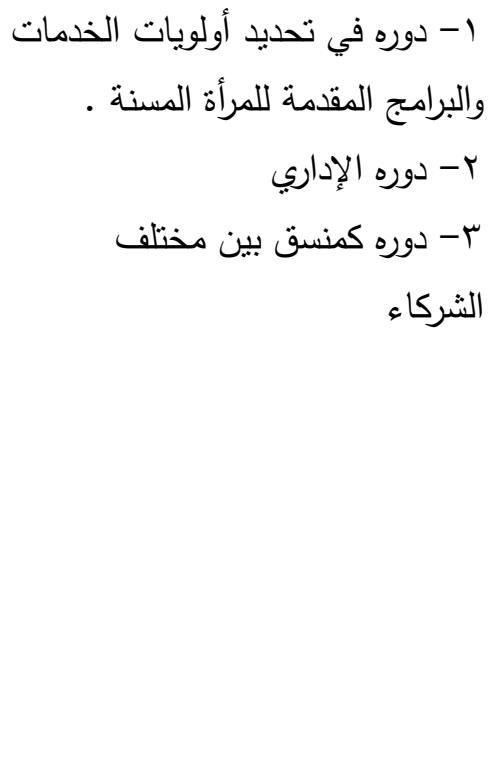 & 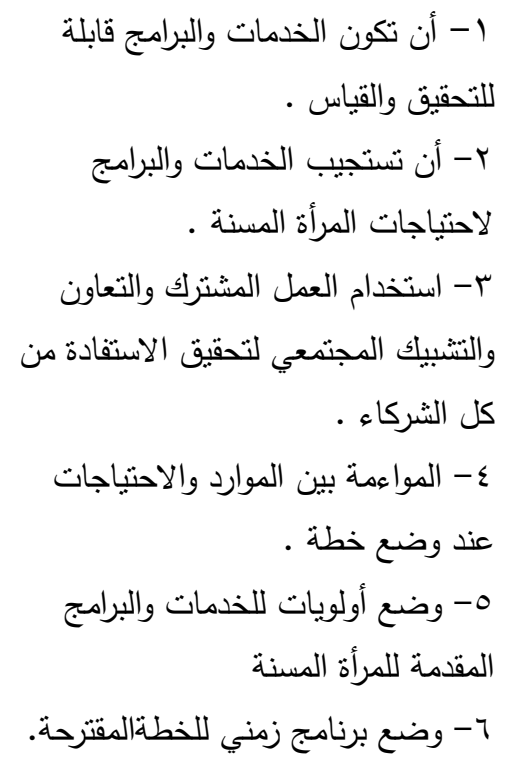 & 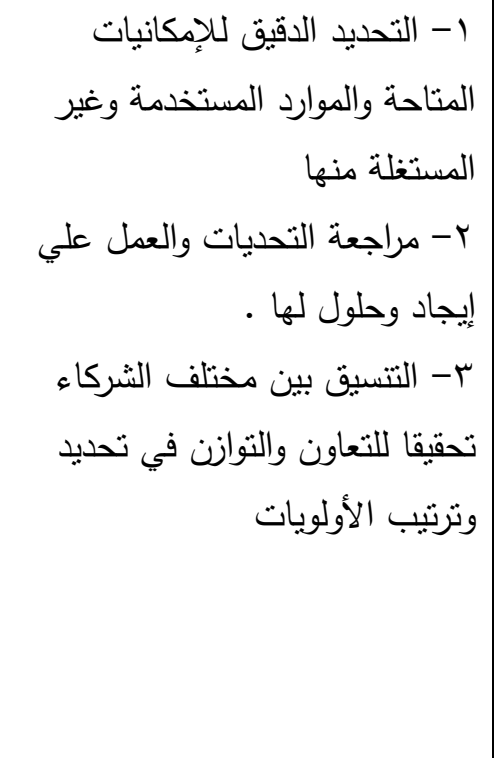 & 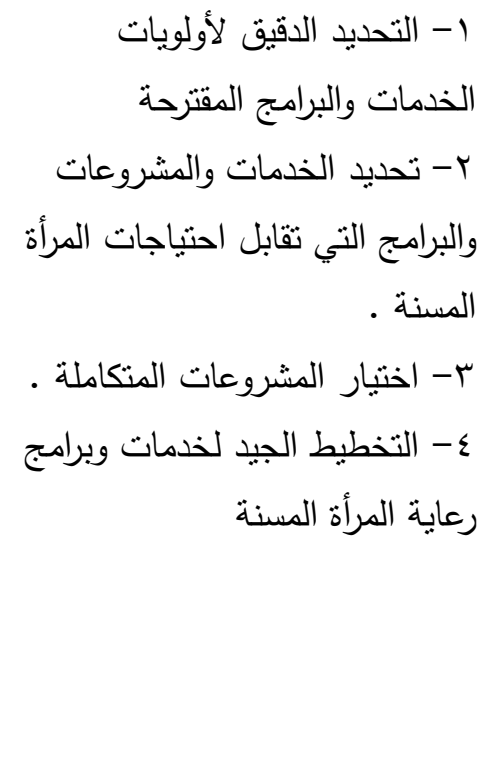 & 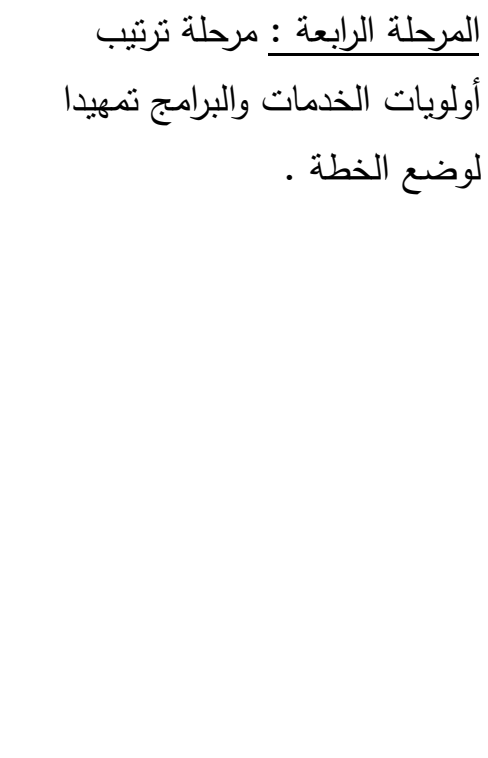 \\
\hline
\end{tabular}




\begin{tabular}{|c|c|c|c|c|}
\hline 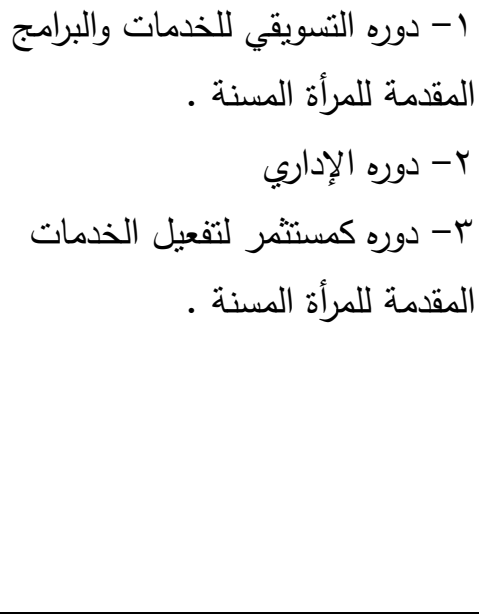 & 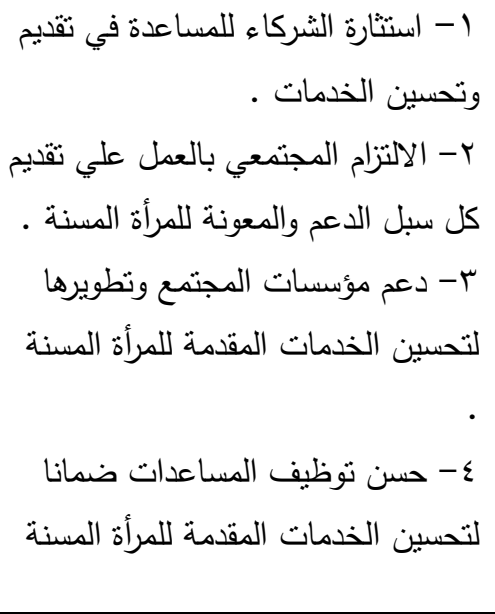 & 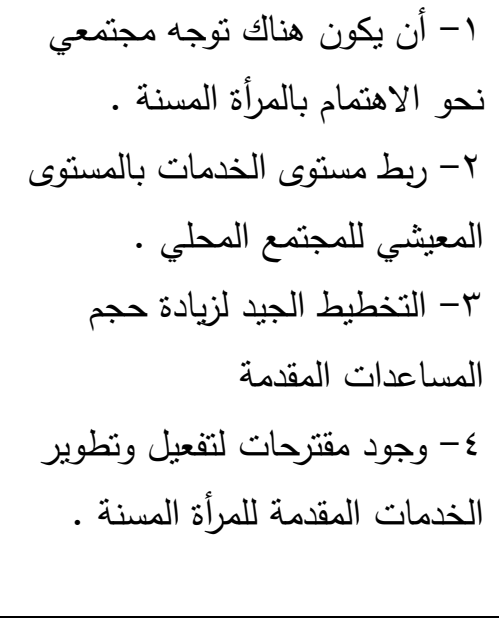 & 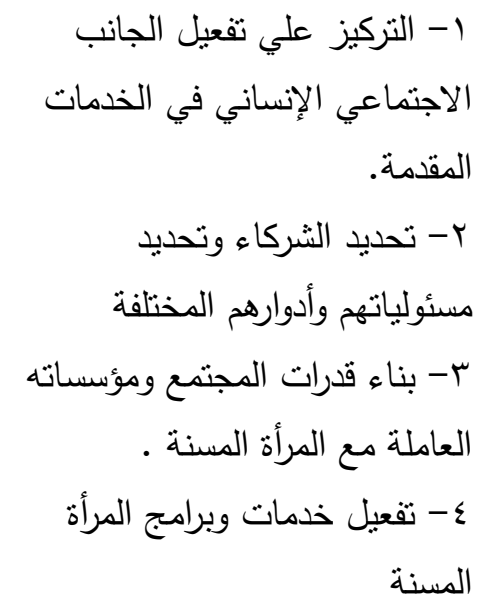 & المجم المساعدات الخامسة : مرحلة تحديد \\
\hline 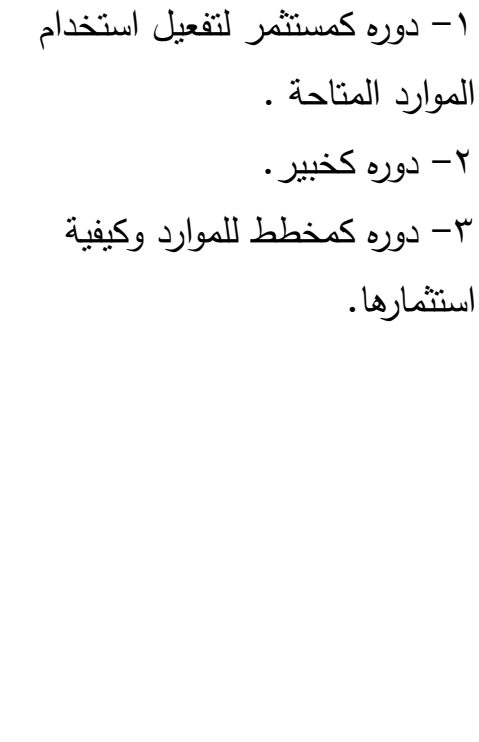 & 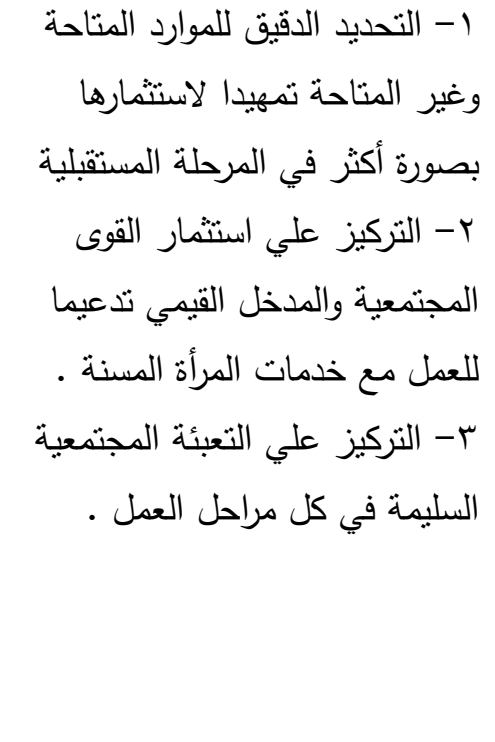 & 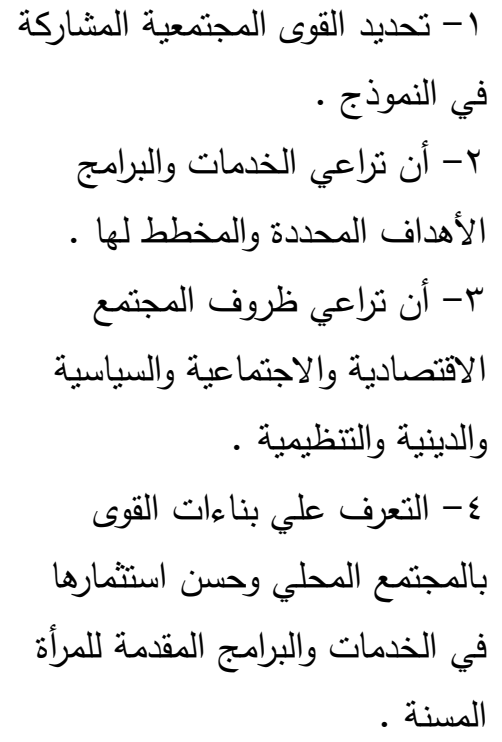 & 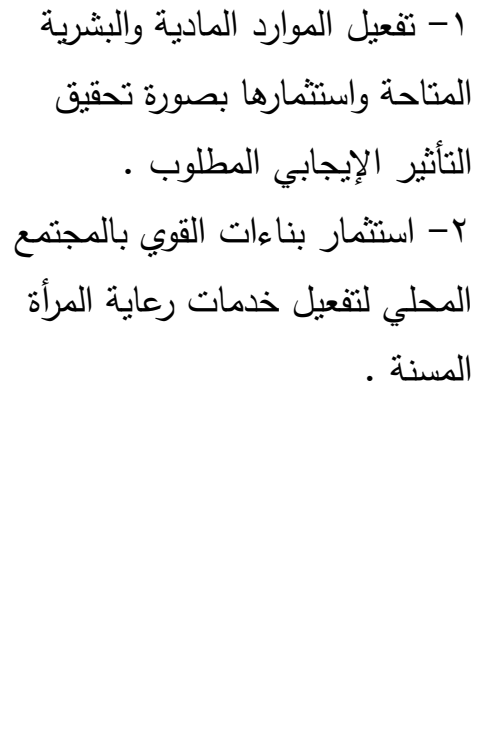 & الميكلة الموارد المادية المادسة : مرحلة إعادة البشرية \\
\hline
\end{tabular}




\begin{tabular}{|c|c|c|c|c|}
\hline r- ا- دوره كخبير. & 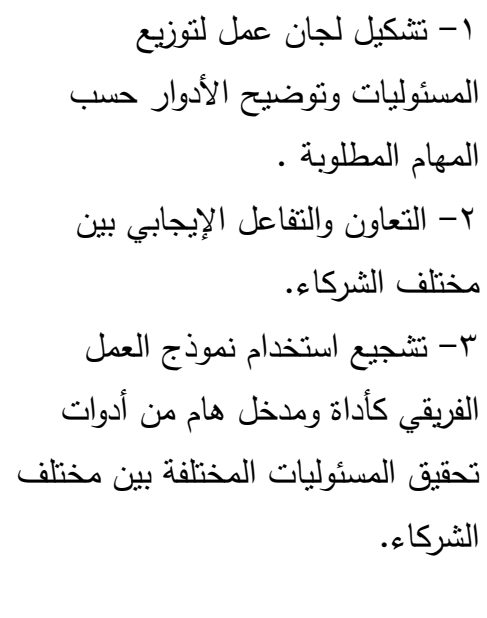 & 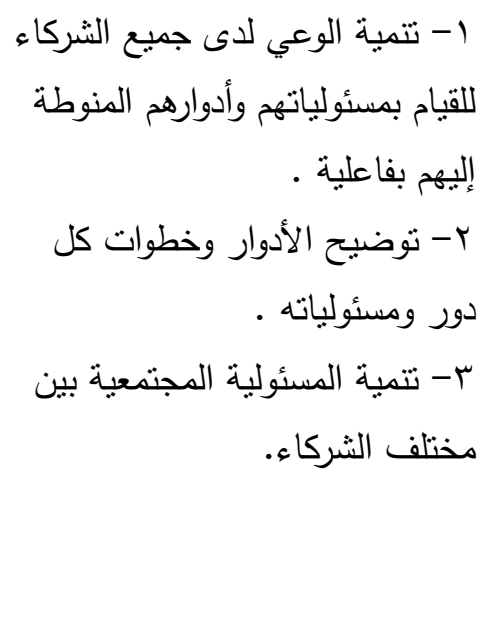 & 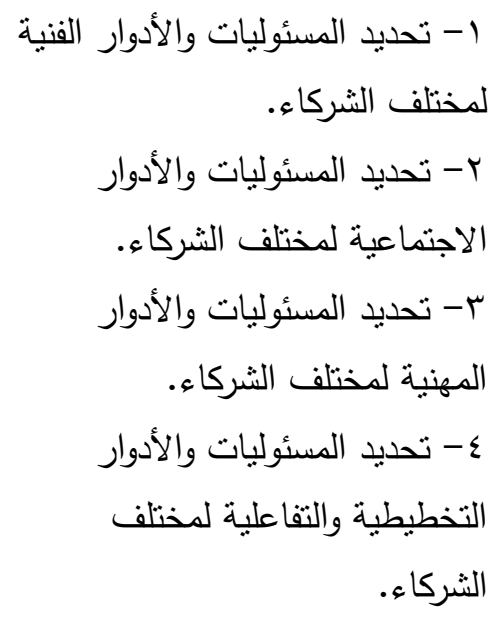 & اللمشاركة فئيات والأدوار المختلفة السابعة : مرحلة تحديد \\
\hline ا المسنة . دوره كمخطط لخدمات المرأة & 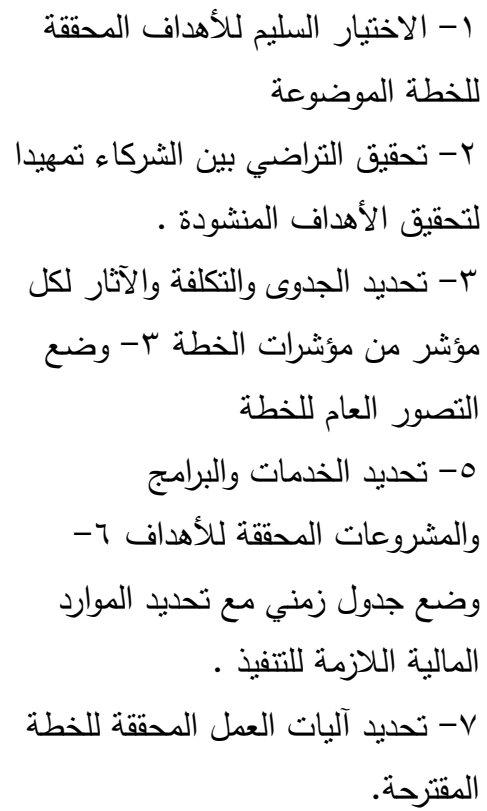 & 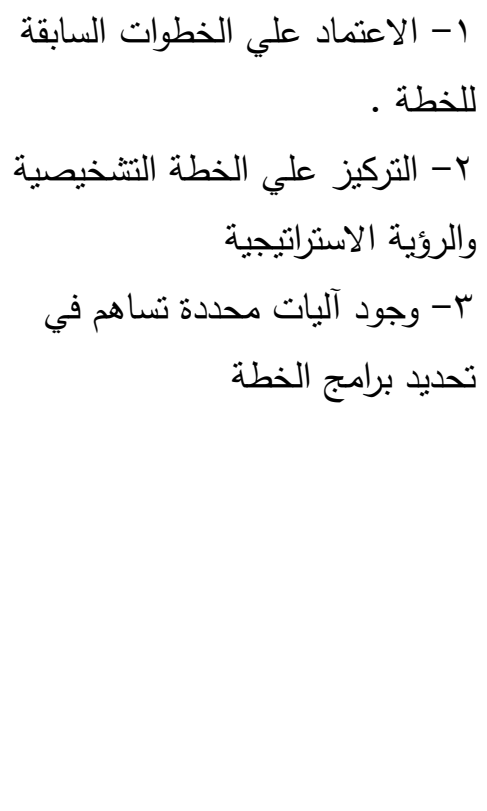 & 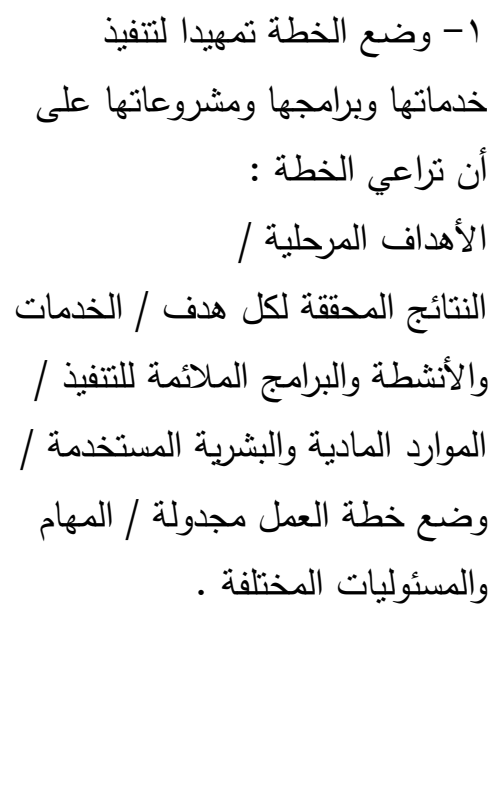 & وتحديد المهام المختلفة للتنفيذ . لمرحلة إعداد الخطة \\
\hline
\end{tabular}




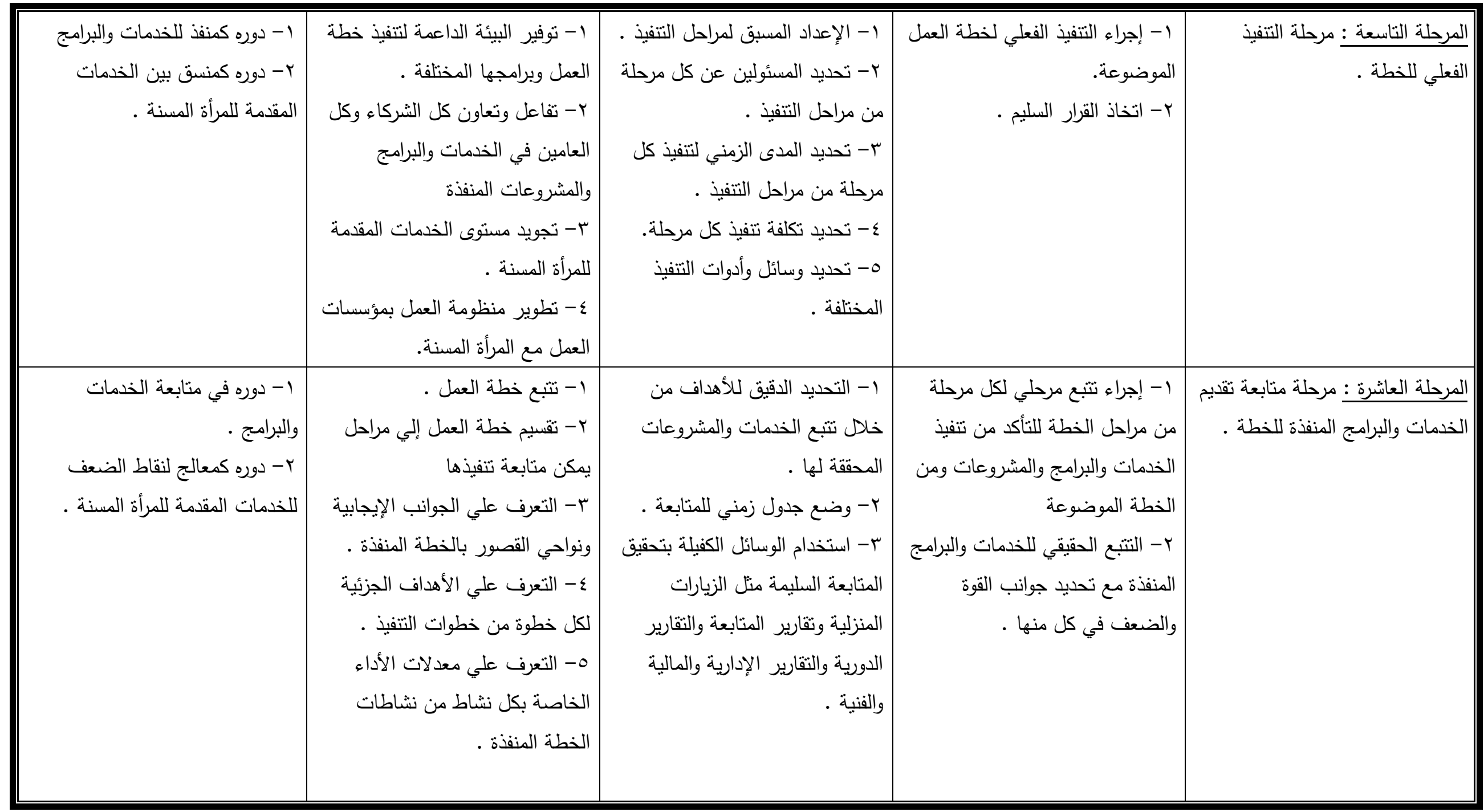




\begin{tabular}{|c|c|c|c|c|}
\hline 1- دوره في تقييم الخدمات والبرامج & 1- اختبار معايير ومحكات التقويم & 1- تحديد محكات ومؤشرات تقييم & 1- قياس الأثر أو العائد للخدمات & المرحلة الحادية عشر : مرحلة \\
\hline ץ- دوره في الارتقاء بمستوى & المناسبة . & الأهداف المحددة للخدمات والبرامج & والبرامج المقدمة للمرأة المسنة وتتشمل & التقويم والاستمرارية \\
\hline الخدمات تحقيقا للاستمرارية . & r- اختبار التصميم المناسب لعملية & r- تحديد محكات تقييم مستوى & أ) قياس الأثر علي المستوى القريب & \\
\hline & التقويم • & الأداء وفاعليته & & \\
\hline & r- جمع وتحليل البيانات ونشر & r- تقويم العائد أو النتائج النهائية & ب) قياس الأثر علي المستوى البعيد & \\
\hline & النتائج · & التي تحققها الخدمات المقدمة للمرأة & r- مراجعة مستوى الأداء والتقويم & \\
\hline & ع- التحضير الجيد للخطة & المسنة . & السليم للخدمات والبرامج المقدمة & \\
\hline & المستقبلية ضمانا لتجويد الخدمات & & للمرأة المسنة . & \\
\hline & وتحقيق الاستمرارية للخدمات المقدمة & & r- تطوير خطط العمل المقدمة & \\
\hline & للمرأة المسنة . & & مستقبلا . & \\
\hline
\end{tabular}


ا - أحمد شفيق السكري : المدخل في تخطيط الخدمات وتتمية المجتمعات المحلية الحضرية والريفية - مفاهيم - أساليب - أدوات - نماذج تطبيقية , دار المعرفة الجامعية , الاسكندرية , .... F م , ص rVr. ץ- أحمد مصطفي خاطر : الخدمة الاجتماعية - نظرة تاريخية - مناهج الممارسة - المجالات , المكتب

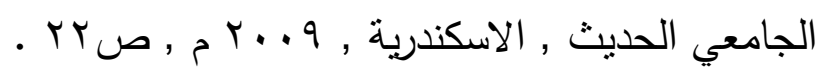

r- أحمد مصطفي خاطر : الخدمة الاجتماعية - نظرة تاريخية - مناهج الممارسة - المجالات , المرجع

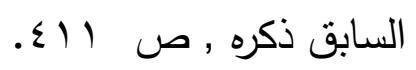

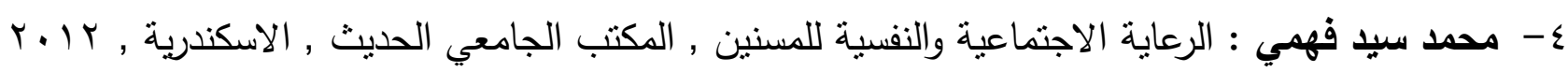

r

- أحمد عبدالفتاح ناجي: سياسة الرعاية الاجتماعية , المكتب الجامعي الحديث , الاسكندرية , V آم ،

צ- مصطفي محمد أحمد الفقي : رعاية المسنين بين العلوم الوضعية والتصور الاسلامي , المكتب الجامعي

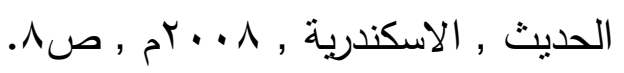

- - عبدالمحي محمود حسن صالح : الخدمة الاجتماعية ومجالات الممارسة المهنية , المكتب الجامعي

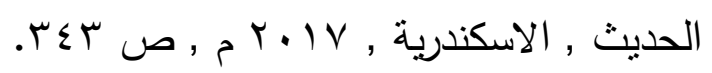

^- قوت القلوب محمد فريد النجار: تقويم برامج الرعاية الايوائية للمسنين بالقاهرة الكبرى , رسالة ماجستير غير منشورة , جامعة القاهرة - فرع الفيوم - كلية الخدمة الاجتماعية , و99 ام • 9- هناء عبد التواب ريبع : تحليل سياسية وزارة الشئون الاجتماعية لرعاية المرأة , رسالة دكتوراه غير منشورة ,

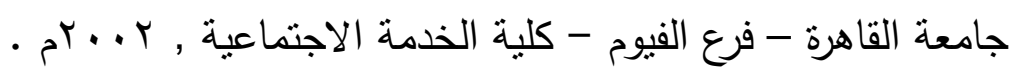

• 1- سلوي عبد الحفيظ بحراوي : فاعلية الخدمات الاجتماعية الغير رسمية للمسنين بالريف , رسالة ماجستير غير منشورة , جامعة القاهرة - فرع الفيوم - كلية الخدمة الاجتماعية ,0 . . بم. ا ا - سمر صبحي عمر يوسف : التخخل المهني من منظور الممارسة العامة للخدمة الاجتماعية لتمكين المسنين بالمؤسسات الايوائية , رسالة دكتوراه غير منشورة , جامعة حلوان - كلية الخدمة الاجتماعية , V. .. م م . r ا - حسن عبد الوهاب محمود عبد الله : كفاءة الاندية النسائية وعلاقتها بتحسين نوعية الحياة , رسالة ماجستير غير منشورة , جامعة الفيوم , كلية الخدمة الاجتماعية , 9 ·. بم • ץ ا - عماد ثرت شرقاوي حسن : الالتزام القيمي لأخصائي الجماعة وتحسين نوعية الحياة للمسنين , مجلة دراسات في الخدمة الاجتماعية والعلوم الانسانية , جامعة حلوان - كلية الخدمة الاجتماعية , العدد ^ץ الجزء

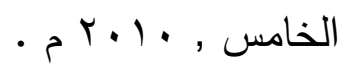


ع ا - مني طه محروس : اختبار العلاقة بين برنامج للتنخل المهني من منظور الممارسة العامة في الخدمة الاجتماعية وتحقيق الدمج الاجتماعي للمسنين , مجلة دراسات في الخدمة الاجتماعية والعلوم الانسانية ، جامعة حلوان - كلية الخدمة الاجتماعية , العدد اس الجزء الرابع , 11 إبم.

1 - هند قباري خميس الجبالي : برنامج للتنخل المهني مع جماعات المسنين وتحسين نوعية حياتهم , رسالة دكتوراه غير منشورة , جامعة حلوان - كلية الخدمة الاجتماعية , 11 أبrم. 7 ا - سالم أبو بكر محمد شعيب : المشكلات الاجتماعية للمسنين وعلاقتها ببعض المتغيرات الاجتماعية , دراسة بيولوجية بشعبية المرج بليبيا , رسالة دكتوراه غير منشورة جامعة المنصورة - كلية الآداب ، سا ـ بام • IV - هالة مصطفي السيد : استخدام المساندة الاجتماعية في تتظيم المجتمع لدعم العلاقات الاجتماعية للمسنين , مجلة دراسات في الخدمة الاجتماعية والعلوم الانسانية , جامعة حلوان - كلية الخدمة الاجتماعية , العدد VT

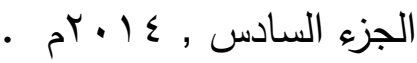

^ا - فاطمة الزهراء عبد ربه أحمد : برنامج تدريبي مقترح لتتمية مهارات التسويق الاجتماعي لجذب المسنين للاستفادة من خدمات أندية الرعاية , رسالة ماجستير غير منشورة , جامعة حلوان - كلية الخدمة الاجتماعية , $\cdot r+10$

9 ا - منال طلعت محمود : دراسات وتطبيقات ميدانية في مجالات الخدمة الاجتماعية - الكتاب الثاني , المكتب

الجامعي الحديث ، الاسكندرية , 10 • م م , ص 17 . 10

• ץ- طلعت مصطفي السروجي , ماهر أبو المعاطي : ميادين ممارسة الخدمة الاجتماعية , الثركة العربية

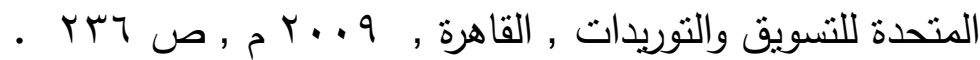
ا اץ- أحمد شفيق السكري : المدخل في تخطيط الخدمات وتتمية المجتمعات المحلية الحضرية والريفية - مفاهيم

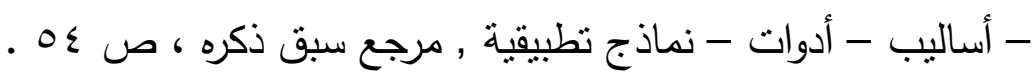
r - - عبد المحي محمود حسن صالح : الخدمة الاجتماعية ومجالات الممارسة المهنية , مرجع سبق ذكره ,

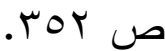

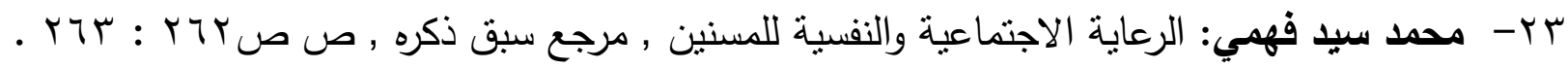
ع ץ- منال طلعت محمود : دراسات وتطبيقات مبدانية في مجالات الخدمة الاجتماعية - الكتاب الثاني , مرجع سبق ذكره , ص ص r rו :rו . ه - أبوالحسن عبد الموجود ابراهيم : التتمية وحقوق الانسان - نظرة اجتماعية , المكتب الجامعي الحديث ،

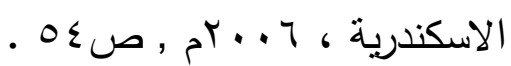
דr- نصيف فهمي منقريوس : النظريات العلمية والنماذج المهنية بين البناء النظري والممارسة في العمل مع الجماعات ، المكتب الجامعي الحديث ، الاسكندرية ، 9 ، . rم , ص و ؟. 
ذكرة ر - أحمد مصطفى خاطر : الخدمة الاجتماعية - نظرة تاريخية - مناهج الممارسة - المجالات , مرجع سبق ذكره , ص ص וr Tr: 